\title{
Article \\ A Comprehensive Uncertainty-Based Framework for Inspection Planning of Highway Bridges
}

\author{
Abdelrahman M. Abdallah ${ }^{1, *}$, Rebecca A. Atadero ${ }^{1}$ and Mehmet E. Ozbek ${ }^{2}$ \\ 1 Department of Civil and Environmental Engineering, Colorado State University, \\ Fort Collins, CO 80523-1372, USA; Rebecca.atadero@colostate.edu \\ 2 Department of Construction Management, Colorado State University, Fort Collins, CO 80523-1584, USA; \\ Mehmet.ozbek@colostate.edu \\ * Correspondence: amkamal@colostate.edu
}

Citation: Abdallah, A.M.; Atadero, R.A.; Ozbek, M.E. A Comprehensive Uncertainty-Based Framework for Inspection Planning of Highway Bridges. Infrastructures 2021, 6, 27. https://doi.org/10.3390/

infrastructures6020027

Academic Editor: Reza Haghani

Received: 18 January 2021

Accepted: 8 February 2021

Published: 11 February 2021

Publisher's Note: MDPI stays neutral with regard to jurisdictional claims in published maps and institutional affiliations.

Copyright: (C) 2021 by the authors. Licensee MDPI, Basel, Switzerland. This article is an open access article distributed under the terms and conditions of the Creative Commons Attribution (CC BY) license (https:// creativecommons.org/licenses/by/ $4.0 /)$.

\begin{abstract}
Bridge inspection standards in the United States require routine visual inspections to be conducted on most bridges at a maximum interval of two years regardless of the bridge condition. Limitations of this uniform calendar-based approach have been reported in the literature. Accordingly, the objective of this study is to provide a new systematic approach for inspection planning that integrates information from bridge condition prediction models, inspection data, and expert opinion using Bayesian analysis to enhance inspection efficiency and maintenance activities. The uncertaintybased inspection framework proposed in this study can help bridge owners avoid unnecessary or delayed inspections and repair actions, determine the inspection method, and consider more than one deterioration process or bridge component during the inspection planning process. The inspection time and method are determined based on the uncertainty and risks associated with the bridge condition. As uncertainty in the bridge condition reaches a defined threshold, an inspection is scheduled utilizing nondestructive techniques to reduce the uncertainty level. The framework is demonstrated on a new and on an existing reinforced concrete bridge deck impacted by corrosion deterioration. The results show that the framework can reduce the number of inspections by $50 \%$ compared to conventional scheduling methods, and the uncertainty regarding the bridge maintenance time is reduced by $16 \%$.
\end{abstract}

Keywords: reinforced concrete; corrosion; bridge decks; cover meter; chloride ion penetration test; nondestructive evaluation; bridge inspection; uncertainty quantification; Bayesian updating

\section{Introduction and Purpose}

In the United States (U.S.), bridge inspections are conducted based on the National Bridge Inspection Standards (NBIS), which were developed by the Federal Highway Administration (FHWA) after the collapse of the Silver Bridge in 1967 [1]. The NBIS requires that, for almost all bridges, a routine inspection should be conducted every two years using visual inspection, and for structurally deficient bridges, annual inspections should be conducted [2]. However, this uniform calendar-based approach was established based on expert judgement 50 years ago without any quantitative justification [3] and several limitations have been reported in the literature [4].

The uniform calendar-based approach does not consider the inspection requirements of a bridge based on its age and deterioration process, which can result in the same inspection interval and procedure for a new or aging bridge [5]. Further, visual inspections are highly subjective, arduous, and depend mainly on the inspector's experience [6]. Visual inspections, if not accompanied by a chain drag test, are limited to surface defects and can only locate subsurface deteriorations (i.e., rebar corrosion, delamination, and voids) that have reached a significant extent and have emerged to the surface of the bridge element [7]. Given the limited information that can be collected from visual inspection, if the inspector suspects a problem with the bridge during routine inspections, Departments 
of Transportation (DOTs) will conduct a more in-depth inspection using more advanced inspection techniques [8]. Repeating inspections with more sophisticated techniques can consume a lot of time and money. Moreover, bridge inspection methods commonly remain constant throughout the life span of the bridge despite the fact that bridge deterioration processes can change over time, which is another major limitation to current inspection practices [9].

On the other hand, the technologies available for bridge inspection and condition evaluation have changed significantly over the past 50 years. For example, nondestructive evaluation (NDE) is an effective enhancement to overcome the limitations of visual inspection. NDE techniques can help predict the bridge performance and establish the internal condition of a structure, such as the likelihood of corrosion in a concrete element, locating subsurface cracks, and detecting fatigue cracks and welding discontinuities in steel members [10]. However, NDE methods are accompanied by inaccuracies or limitations and cost, meaning they should be strategically deployed [11].

In addition to adopting new methods for inspection, several studies have been developed to help predict the deterioration process of bridges. Deterioration prediction models are commonly used to capture the condition of the bridge and schedule bridge maintenance accordingly [12]. However, deterioration models can also help in selecting the inspection time and adjusting the inspection techniques depending on the predicted bridge condition [13]. Parameters used in the prediction model can be highly variable depending on the uncertainty in the properties of the bridge; therefore, probabilistic approaches should be considered during the decision process [14]. Given the limitations of current inspection practice and recent innovations in bridge design and technology, the FHWA is currently encouraging DOTs to improve the efficiency of bridge inspections and move away from the fixed calendar-based inspection interval to a more rational approach that depends on the risks associated with the bridge condition and in-service environment [15].

The objective of this study is to provide a systematic approach for integrating information from bridge condition prediction models, NDE inspection data, and expert judgement to enhance the understanding of bridge condition, allowing for a more efficient use of inspection resources and better decision making about maintenance activities. As a result, this study developed a new uncertainty-based inspection planning framework that enables bridge inspection planners to determine the inspection time and technique based on the bridge condition. The novel premise of this study is that bridge inspections are conducted to provide knowledge about the bridge's current condition and therefore an inspection should only be conducted when the level of uncertainty about the bridge condition is higher than a certain threshold.

This study contributes to the body of knowledge in bridge management research by providing a novel and rational alternative for bridge inspection planning to the currently utilized uniform calendar-based approach [2]. This study helps in improving the bridge management process by providing a framework for managing different data sources and using those for inspection and maintenance planning. From a practice standpoint, adopting the proposed framework will result in utilizing inspection resources more efficiently and improving bridge safety and serviceability because the presented methodology can help bridge owners (1) avoid unnecessary or delayed inspections and repair actions, (2) combine both routine and in-depth inspections with a single valuable inspection that utilizes the capabilities of NDE methods, and (3) consider more than one deterioration process or bridge component during the inspection planning process.

In the framework, the inspection time is determined by quantifying the uncertainties associated with the prediction model and the probability of an element transitioning to a certain phase of deterioration during the life cycle of the bridge. Selecting the inspection technique depends on the stage in the bridge element's service life and how effectively the technique can reduce the uncertainty about the bridge condition. After an inspection is conducted, the new inspection data are used to update the deterioration model using 
Bayesian updating, and the updated deterioration model is used to inform a more accurate prediction of the next inspection and repair time.

Bridge decks play a significant role in representing the serviceability and safety of a bridge since they are part of the primary load path for the whole system [5]. Therefore, from a scoping perspective, the focus of this study will be on reinforced concrete (RC) decks that are exposed to chloride-induced corrosion. RC decks are considered the most expensive bridge components, requiring regular maintenance and rehabilitation; therefore, accurate evaluation and inspection planning are significant [16]. However, it should be noted that the framework presented in this paper is flexible and can be applied to different bridge components with different materials and structural systems.

\section{Inspection Planning: Literature Review}

Due to the importance of inspections and their connection to the safety of the structure and maintenance decisions, in the last few decades, research in the field of inspection planning has been performed extensively, using different approaches such as optimizationbased methods, reliability theory, and risk analysis using the value of information (VoI) and expert judgement. This section analyzes the research effort that has been conducted in the field of bridge inspection planning and the frameworks that have been proposed.

\subsection{Optimization-Based Methods}

In inspection planning, different objectives in both single- and multi-objective optimization problems have been considered such as minimizing the expected damage detection delay, minimizing the probability of failure, maximizing the extended service life, and minimizing the expected total life cycle cost [17]. Deterioration models are used in the optimization process to capture the deterioration mechanism $[18,19]$ and the probability of detection (PoD) is used to quantify the quality of different inspection methods [20].

An optimization process was presented by Kim and Frangopol [21] to find the optimum inspection times and method for inspecting a concrete bridge exposed to corrosion. The study concluded that an increase in the number of inspections or improving the inspection quality will reduce the expected damage detection delay but will increase the inspection cost. In a bi-objective optimization process, Kim and Frangopol [22] found that for fatigue-sensitive structures, if minimizing the cost of a structure failure was an objective in the optimization process, the cost of high-quality inspections will be justified, and if more than two inspections are to be conducted, using NDE methods with a higher quality in the early stages of the bridge service life followed by lower-quality methods later in the service life is the most cost-effective.

Kim, Frangopol and Soliman [13] extended the optimization process presented in [21] to find the effect of minimizing the damage detection delay on the repair activities of RC bridges. Kim, Frangopol and Soliman [13] found that conducting high-quality inspections combined with early preserving maintenance can be cost-effective and will extend the service life of the bridge. The discussed frameworks focused on providing an inspection plan for a single structure component; therefore, Soliman, et al. [23] provided an inspection planning approach for a steel bridge with multiple fatigue-sensitive details. It was noted by the authors that the optimizer chooses the low-quality inspections to be performed later since they will have a higher PoD and cracks will be larger and easier to detect. Their findings agreed with Soliman and Frangopol [24], where a Bayesian updating process and inspection outcomes were incorporated in the planning framework to choose the appropriate inspection and repair time. Other optimization planning frameworks with more than two objectives were presented by Kim, et al. [25], where redundant objectives were identified and omitted to enhance the optimization process.

Drawbacks of optimization-based approaches have been noted in several studies such as the following: considering more than one time-dependent deterioration mode is very complex [21]; the processes can be very sensitive to the deterioration model inputs [13]; and incorporating inspection results in the decision process to update the inspection sched- 
ule will require an expensive computational effort [26]. Further, the PoD functions that have been used in several inspection planning studies [20] can be difficult and expensive to determine for an NDE method since NDE methods are based on experimental tests which do not represent the onsite conditions and have to be repeated several times for the same material for each NDE method.

\subsection{Reliability-Based Methods}

Reliability concepts have been proposed in many studies as an approach for maintenance planning, where maintenance should be considered when the structure reaches a defined limit state. However, some studies propose inspection planning frameworks using reliability theory and lifetime functions, in order to avoid a structure failure and delayed maintenance [27]. Kwon and Frangopol [28] proposed a combined approach that integrates a fatigue reliability model (FRM), crack growth model curves (CGM), and a PoD model to predict fatigue crack growth propagation with time and to schedule inspections and repair actions. Using a similar reliability approach, Dong and Frangopol [29] suggested that inspections or repairs do not have to be performed on the whole structure at one time but can focus on a specific component to reduce the inspection cost and improve the inspection quality, which supports the ideas presented by [30].

Before Dong and Frangopol [29], Orcesi and Frangopol [31] incorporated lifetime functions in the reliability analysis process and found that inspection schedules and methods do not have to be the same for the whole structure. This means that for highly critical bridge elements, inspection techniques can be improved compared to less important or more redundant elements. Further, Soliman and Frangopol [32] used lifetime reliability functions to schedule inspection times, based on pre-defined threshold values. This time, Bayesian updating was utilized to update the fatigue model parameters using inspection outcomes and update inspection times. One of the main limitations of the studied reliability-based inspection frameworks is that they focus on the safety of the structure and time of failure without considering its serviceability or consequences of a failure [33]. Moreover, in some cases, the capacity and the applied loads on the structure have to be predicted which can lead to inaccuracies in the decision process [34].

\subsection{Risk-Based Methods}

There is always a probability that the structure fails during operation and the consequence of this component or structure failure depends on its redundancy and criticality. Risk-based inspection (RBI) is based on quantifying the risk associated with an element or system failure by considering the probability and consequence of a failure in terms of both serviceability and safety. The consequence of a structure failure can be quantified using mathematical concepts such as the value of information (VoI) or expert judgments. Liu and Frangopol [35] presented a risk-based framework for inspection scheduling that will assist decision makers achieve the maximum value of information using Bayesian theory. Their results agreed with the findings of Agusta, et al. [36] that NDE methods with a higher PoD provided a higher value of information at earlier stages of the structure service life and reduced the risk of failure.

Based on the Bayesian analysis and algorithms presented by [37,38], Yang and Frangopol [26] presented a pre-posterior analysis with assumed inspection scenarios to choose the inspection time and method that will minimize the posterior life cycle cost and provide the highest VoI. The analysis indicated that the life cycle cost decreases when budgets for inspection and repair increase. However, to calculate the VoI, long-term projections of the expected outcomes from different inspection and maintenance scenarios have to be conducted, which can cause several inaccuracies and uncertainties if these projections are made for a long time in the future. Thus, without having to consider the whole life cycle of the system, Haladuick and Dann [39] presented a framework that uses the VoI to help inspection planners in selecting the inspection technique for only the next inspection time. 
Most of the risk-based inspection frameworks discussed in this section required expensive computational efforts and did not incorporate the experience or judgment of bridge engineers, unlike the work presented by Washer, Nasrollahi, Applebury, Connor, Ciolko, Kogler, Fish and Forsyth [5], which was a simple method for inspection planning based on a rational and qualitative risk analysis. The planning program involves evaluating the likelihood and consequences for a certain damage to occur using an expert panel of experienced engineers in the field of bridge engineering. Based on the bridge's risk characteristics, an inspection interval was assigned to the bridge using a risk matrix. Although this framework is simple and can be easily applied in practice, it can be subjective and affected by the judgement of the expert panel, which is relatively a similar limitation to other approaches that were based on expert judgement such as the one presented by Parr, et al. [40]. Using a more quantitative approach and statistical data analysis, Nasrollahi and Washer [41] presented a study where bridge inspection intervals were decided using archived NBI rating data collected during routine bridge inspections. The purpose of this analysis was to determine the length of time a bridge will stay in a certain condition before deteriorating to a lower condition and performing inspections during this time span.

\subsection{Research Gaps}

In a previous paper presented by Atadero, et al. [42], uncertainty-based inspection was introduced but did not consider lifetime functions, different types of deterioration at the same time, or pre-posterior analysis for choosing the next inspection method, and such as other studies, a guide for choosing uncertainty thresholds was not provided. Research in the field of bridge inspection planning and scheduling has covered a wide range of ideas and approaches, but to the authors' knowledge, uncertainty quantification methods in the inspection planning process have not been used or analyzed using a detailed application in the same way that is presented herein. Further, none of the presented frameworks have yet been applied in practice, and until now, bridge owners continue to rely on the twoyear routine inspection program, followed by in-depth inspection if required. The lack of adoption could be due to the complexity of the proposed inspection planning approaches, the skills required for applying the methodologies, the desire to eliminate engineering judgment which is found in some of the inspection planning frameworks, and/or focusing only on the life cycle of the structure which, in some cases, can be unnecessary and full of uncertainty as one moves longer into the lifetime of the structure. Moreover, considering more than one deterioration process in the inspection planning phase is important but can be difficult to implement in most of the presented studies [43].

Given these limitations and research gaps, this study proposes a computationally simple and easily implementable (i.e., practical) methodology for bridge inspection planning that can help address some of the research gaps and be applied in practice. The uncertaintybased inspection methodology is flexible and can be adapted to consider different bridge components and deterioration mechanisms. To minimize subjectivity and complexity, the framework integrates simple quantitative methods and engineering judgment simultaneously in the planning process.

\section{Decision Framework for Uncertainty-Based Inspection Planning}

It is important that bridge owners know the condition of their bridge stock and how the condition will deteriorate with time to be able to effectively plan for inspections and repair actions. However, determining the inspection time and technique is a nontrivial problem with several uncertainties and contradicting objectives [35]. Uncertainty in the bridge condition arises from various aspects, such as environmental conditions surrounding the bridge and from the properties of the bridge itself, and typically increases over time. Limitations of tools used to analyze bridge performance such as the accuracy of inspection techniques and the variability of parameters used in a prediction model also contribute to uncertainty in establishing the bridge condition. Thus, bridge owners must 
be aware of the different sources of uncertainty and try to reduce that uncertainty to a limit where appropriate actions and decisions can still be taken.

The uncertainty-based inspection framework is based on two main concepts: (1) bridge inspections should be performed when the degree of uncertainty regarding the bridge condition reaches a defined threshold and (2) inspection methods are determined based on how well a technique can reduce the uncertainty regarding the bridge condition and improve the prediction of the deterioration model. Figure 1 provides a summary of the proposed framework and the tasks required to determine the inspection time and methods. The following sections will explain the framework in detail.

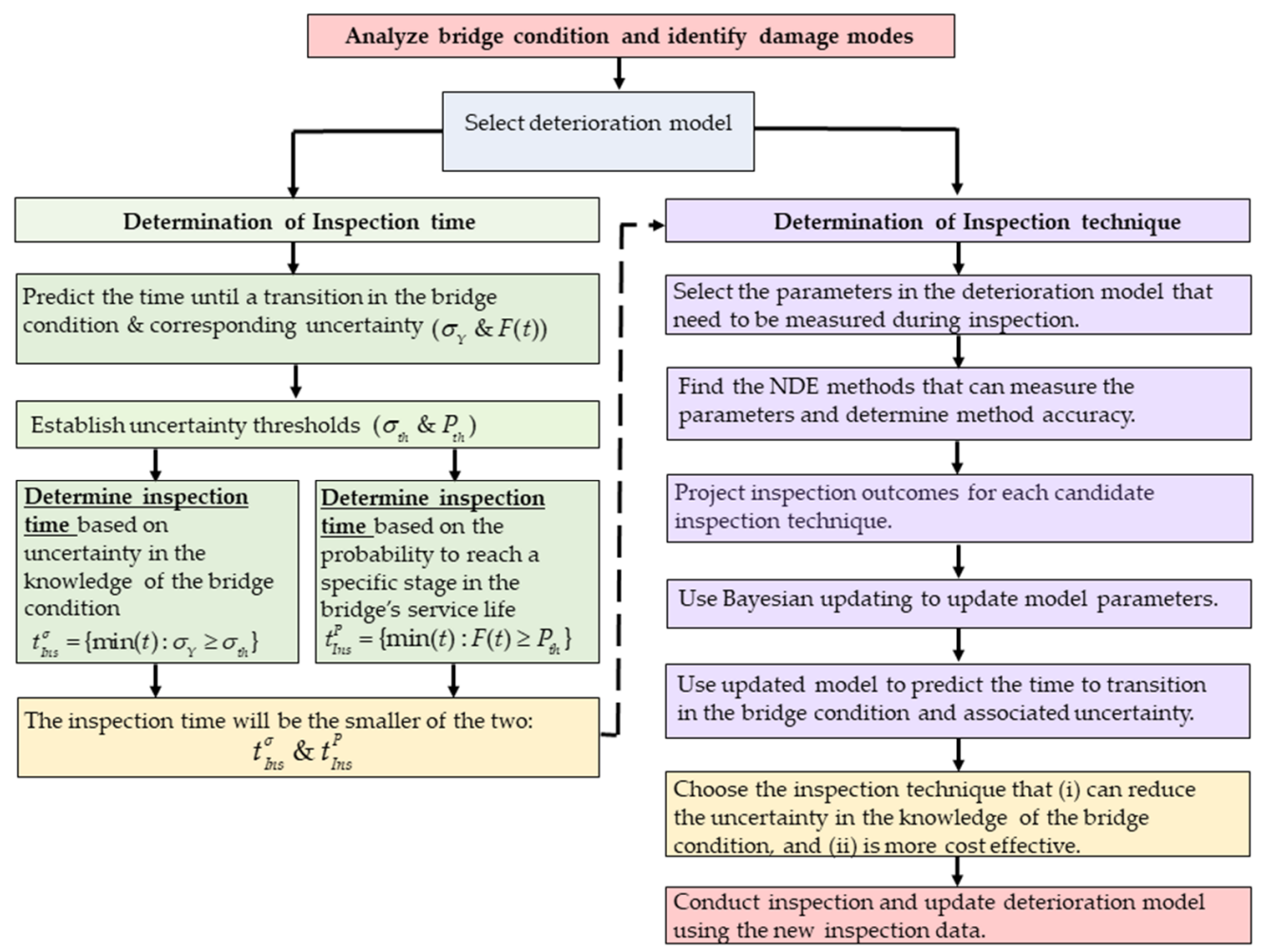

Figure 1. Uncertainty-based inspection framework.

\subsection{Indicator of Bridge Condition}

In current bridge inspections, the condition of the bridge is evaluated using mainly the NBI rating system [44] or the AASHTO element level system [45]. In the NBI rating system, the condition of the bridge components (i.e., concrete deck or piers) is reported on a scale from 0 to 9 , in which 0 and 9 describe a failing and a new component, respectively [44]. In the AASHTO element level system, the performance of bridge elements is rated using mainly four condition states (CS): good (CS1), fair (CS2), poor (CS3), and severe (CS4) [45]. The quality and accuracy of the information and rating provided in the bridge inspection report depend mostly on the experience and training of the bridge inspector which, in some cases, might be inaccurate and subjective [6]. Further, in the current bridge rating systems, the language used to describe the component condition is qualitative and might be understood differently by different bridge inspectors, leading to several uncertainties and inconsistencies [6].

Accordingly, this paper will demonstrate a different approach where the condition of the bridge is represented in terms of the time to transition (TTT) which is the predicted time for the bridge element or component to reach a certain phase or condition in its service life. The TTT is a quantitative measurement estimated based on the information provided from both prediction models and collected inspection data, which can help in minimizing subjectivity and ambiguity among bridge inspectors and improve the quality 
of the recorded inspection data. Moreover, the core value of a bridge inspection is to support bridge owners in their management decisions. Most bridge management systems (BMSs) are used to project the time for a bridge element condition to transition from one stage to another, in order to decide on an appropriate maintenance time. Similarly, the TTT provides a flexible indicator of the bridge condition, which can represent the time from the beginning of the bridge service life until reaching a certain condition, or the time between different stages in the bridge service life. For example, the TTT could be the time from opening the bridge until corrosion initiation or crack propagation, or it could be the time from corrosion initiation until corrosion cracks propagate on the surface. The TTT can be adjusted to fit different bridge systems, deterioration mechanisms, and materials, such as the time for corrosion propagation in concrete decks and the time for fatigue cracks to reach a certain size limit in steel details.

Further, different bridge elements can spend a long period of time in the initial stages of deterioration, where the deterioration rate is slow. During this time, the bridge element condition is changing, but bridge inspectors are not able to document any sign of deterioration. For instance, chlorides in concrete decks might spend a long period accumulating in the concrete substrate without showing any signs of deterioration for bridge inspectors to report, as well as not providing any chance for bridge owners to perform preventive maintenance. Considering these initial phases of deterioration using the TTT concept and the presented framework will help bridge owners make timely and accurate inspection and maintenance decisions, as the TTT can also be set as the time when a maintenance activity should be conducted. In addition to identifying the appropriate maintenance time, the TTT will help a bridge inspection planner track the different stages of the bridge service life so they can decide on prediction models and NDE methods that are appropriate to capture and measure the deterioration process during a defined phase in the bridge life cycle.

Overall, evaluating and reporting the TTT for a bridge component is an essential step in the proposed framework; however, the TTT does not replace the NBI or AASHTO rating system $[44,45]$. In fact, it can be used along with the other rating systems to enhance the data gathered during inspections and the quality of the inspection reports.

\subsection{Choosing Inspection Time}

To choose the next inspection time using the uncertainty-based inspection framework, a bridge inspection planner should select a prediction model able to capture the deterioration mechanism and predict the TTT and then quantify the uncertainty in the model prediction and compare the model uncertainty with the uncertainty thresholds to select the next inspection time.

\subsubsection{Properties of Deterioration Model and Corresponding Uncertainty}

The framework starts by analyzing the structure properties, in-service environment, and inspection and maintenance records, if available, to establish the deterioration mechanisms that are most likely to affect the bridge performance. Based on the identified deterioration mechanisms, appropriate prediction models that can describe and predict the uncertainty in the time-dependent deterioration process are adopted. For example, in this paper, three mechanistic deterioration models, as detailed in Appendix A, will be utilized to predict (1) the corrosion initiation time, (2) the time for corrosion cracks to reach a certain size, and (3) the time needed for corrosion to reach a certain depth in the steel reinforcement. Moreover, the proposed framework seeks to select the inspection method based on the ability of the method to reduce uncertainty. Therefore, it is important to choose a model that has parameters that can be refined and updated using inspection measurements (i.e., NDE inspection data), which will reduce the level of uncertainty associated with the prediction model.

To consider uncertainty in a deterioration model prediction, a probabilistic approach should be used. One can assume that $\mathrm{Y}(\mathrm{t})$ is a random variable representing the bridge 
condition at time $\mathrm{t}$ or the TTT and $\mathrm{y}(\mathrm{t})$ represents the corresponding realization. A suitable deterioration model can be used to predict $\mathrm{Y}(\mathrm{t})$ at any future time $t$ including the model uncertainties. Therefore, a general form for the deterioration model can be expressed as [42]

$$
y(t \mid \theta)=M_{d}(t ; \theta)
$$

where $M_{\mathrm{d}}(\mathrm{t} ; \theta)$ is the deterioration model and $\theta$ is the uncertain model parameters (e.g., material properties, environmental exposure, use of deicing salt, loading conditions) with a probability distribution function $(\mathrm{PDF}) \mathrm{f}(\theta)$ for each random variable representing the prior information a bridge inspector has about the parameters. By propagating the uncertainty in the model parameters $\theta$ using an appropriate computational method (e.g., Monte Carlo simulation or importance sampling), we can establish the associated uncertainty in the prediction of $\mathrm{Y}(\mathrm{t})$. The time to reach a certain bridge condition (i.e., TTT) can be probabilistically represented using a PDF or can be characterized using a mean $\mu_{\mathrm{TTT}}$ and standard deviation $\sigma_{\mathrm{TTT}}$. It should be noted that the framework is general and, depending on the problem, any deterioration model (i.e., stochastic or mechanistic) that fulfills the aforementioned requirements can be implemented in the planning process.

\subsubsection{Criteria Used to Choose Next Inspection Time}

Based on the results of the prediction model, the bridge inspector can choose the inspection time considering two criteria, (1) the level of uncertainty in the predicted bridge condition before the TTT and (2) the probability to reach the TTT using lifetime functions. In this paper, the inspection time will be denoted by $t_{I n s, N}$, where $N$ is the number of the inspection in a sequence of inspections.

Statistical descriptors such as the standard deviation $\sigma_{Y}$ or coefficient of variation $\mathrm{COV}_{Y}$ can be used to quantify the uncertainty in the results of the deterioration model. For the first criterion, we start by predicting the time for the bridge to reach a series of specific conditions before the TTT and quantifying the uncertainty in the prediction results using the aforementioned statistical descriptors. Then, to determine the inspection time based on the first criterion, let $\sigma_{\text {th }}$ denote the threshold (i.e., upper bound) for $\sigma_{Y}$. The corresponding inspection time can be selected as the first expected time that $\sigma_{Y}$ equals or exceeds $\sigma_{t h}$, i.e., $t_{\text {Ins }}^{\sigma}=\left\{\min (t): \sigma_{Y} \geq \sigma_{t h}\right\}$. To explain further, let us consider that the TTT will be the time to reach a crack size of $10 \mathrm{~mm}$. Then, to propagate the uncertainty with regard to the bridge condition, we will calculate the expected or average time $(E[t])$ to reach different crack sizes before reaching $10 \mathrm{~mm}$ (TTT), for example, 2, 3, and $5 \mathrm{~mm}$ and the corresponding $\sigma_{Y}$ at each crack size which will be expressed as a unit of time (years, months, etc.). Then, at the time $\sigma_{Y}$ exceeds $\sigma_{\text {th }}$, an inspection has to be considered.

For the second criterion, lifetime functions will be used to calculate the probability of a bridge reaching a defined stage in its service life. Several lifetime reliability functions have been successfully used as performance indicators in the field of asset management [27]. One of the main lifetime functions is the cumulative probability of failure which will be used in this paper as the cumulative probability of transition, in order to choose the inspection time. The cumulative probability of transition $\mathrm{F}(\mathrm{t})$ is defined as the probability that the TTT to the Kth stage of the service life of a bridge component is less than or equal to the time $t$ and is expressed in Equation (2), where $f($.$) is the PDF of the TTT:$

$$
F(t)=P(T T T \leq t)=\int_{0}^{t} f(x) d x
$$

To select the inspection time based on the second criterion, let $\mathrm{P}_{\text {th }}$ denote the threshold (i.e., upper bound) for $\mathrm{F}(\mathrm{t})$; then, the corresponding inspection time can be selected as the first time that $F(t)$ exceeds $P_{t h}$, i.e., $t_{I n s}^{P}=\left\{\min (t): F(t) \geq P_{t h}\right\}$. Finally, the bridge inspector should choose the smaller $t_{\text {Ins }}^{\sigma}$ or $t_{\text {Ins }}^{P}$ as the next inspection time.

Another issue that needs to be considered when scheduling the next inspection time is the fact that bridges may be subjected to several modes of deterioration simultaneously. 
These deterioration mechanisms can be related; for example, in the case of cracks on the surface of a concrete deck and loss of the cross-sectional area in the steel reinforcement, both phenomena are due to corrosion. Conversely, the deterioration processes can be unrelated such as corrosion of the concrete deck and fatigue of steel details and can still be considered using this framework. If two deterioration mechanisms $\mathrm{g}_{1}$ and $\mathrm{g}_{2}$ affect the bridge performance, a bridge inspection should be considered whenever the cumulative probability of transition of each deterioration process, $\mathrm{F}(\mathrm{t})_{\mathrm{g}_{1}}$ or $\mathrm{F}(\mathrm{t})_{\mathrm{g}_{2}}$, reaches $\mathrm{P}_{\text {th }}$ or the standard deviation, $\sigma_{Y, g_{1}}$ or $\sigma_{Y, g_{2}}$, exceeds its threshold. Accordingly, a bridge inspector will have four inspection times to choose from; therefore, based on a more conservative and crude decision, the $t_{I n s, N}$ should be the minimum of all four inspection times.

\subsubsection{Determining the Uncertainty Thresholds Using an Expert-Based Assessment Process}

The selected uncertainty thresholds $P_{\text {th }}$ and $\sigma_{\text {th }}$ will control the inspection time and, ultimately, the number of inspections conducted over a bridge's service life. Smaller threshold values will lead to more inspections, and higher threshold values will lead to fewer inspections. The selection of the threshold values depends on the bridge owner's attitude towards uncertainty and the risk associated with bridge component failure. This section will present an expert-based assessment process that can guide bridge inspectors to establish the uncertainty thresholds $\left(\mathrm{P}_{\text {th }}\right.$ and $\left.\sigma_{\text {th }}\right)$ using engineering judgement and information about the bridge. This process helps bridge inspection planners consider the current rating of the bridge $[44,45]$ and the risks associated with the bridge condition when planning inspections. The following paragraphs will explain the steps required to choose the uncertainty thresholds.

Step 1: Identify damage modes: The assessment process starts by identifying the damage modes that have the highest impact on the bridge component and the inspection time, and this can be conducted based on the experience of the bridge owners with similar bridge components and in-service environments. In this paper, the damage mode considered will be corrosion of reinforced concrete decks. Other damage modes such as fatigue cracking can be considered depending on the bridge condition.

Step 2: Identify performance factors and consequence factors: To consider the risks associated with the bridge condition, bridge inspection planners need to identify the "performance factors" and "consequence factors". The performance factors represent the bridge design and construction characteristics that have an impact on the rate of the damage accumulation. The consequence factors represent the outcomes if the bridge component failed.

The seven performance factors that were considered in this study are (1) the deck drainage system and ponding, (2) year of construction and/or replacement maintenance, (3) protective layer over concrete surface, (4) bridge skewness, (5) average daily truck traffic (ADTT), (6) subjectivity to overspray of deicing salt or water, and (7) type of reinforcement. More information about the selected performance factors and how they contribute in the corrosion damage mode can be found in $[5,40]$. There are other factors that can impact the corrosion rate that were not considered in the performance factors because they are already considered through the deterioration models described in Appendix A. A bridge inspection planner should not include a factor that was already considered in the deterioration models or in the bridge rating process $[44,45]$ to avoid overestimating the impact of a single factor on the decision process by considering it multiple times.

When choosing the uncertainty threshold, the severity of outcomes associated with bridge component failure should be analyzed. Herein, four consequence factors were considered: (1) damage to the top of the bridge, (2) features under the bridge, (3) effect of the damage on the structural capacity, and (4) the availability of alternative routes. The study will focus on the consequence of bridge deck failure due to corrosion while considering the four consequence factors. A total of eleven factors were considered in this paper (seven performance factors and four consequence factors). 
Step 3: Assign initial score based on current bridge condition: To consider the current bridge condition and previous inspection results, an initial score is assigned to the bridge based on the NBI [44] or AASHTO element level rating [45] of the bridge component. This score is calculated using the total number of performance and consequence factors (P\&C factors), as shown in Table 1. Incorporating the NBI [44] or AASHTO [45] rating of the bridge helps bridge owners in applying the uncertainty-based inspection framework to existing bridges with archived inspection records or new bridges.

Table 1. Initial score assigned for bridge component based on the rating system and number of performance and consequence $(\mathrm{P} \& \mathrm{C})$ factors.

\begin{tabular}{ccc}
\hline NBI Condition Rating [44] & AASHTO Rating System [45] & Score Assigned \\
\hline 7 or higher & CS1 & Number of factors $\times 10$ \\
\hline 6 & CS2 & $($ Number of factors -3$) \times 10$ \\
\hline 5 or less & CS3 or CS4 & Considered a low category \\
\hline
\end{tabular}

A bridge with a rating of 7 or higher will be assigned the maximum initial score, which in this study will be 110 (the eleven P\&C factors multiplied by 10), and for a bridge with an NBI rating of 6 , an initial score of 80 will be assigned. A bridge with an NBI rating less than or equal to 5 will be directly considered in the low category without continuing the assessment process. The rationality of this calculation procedure will be explained further in Steps 4 and 5.

Step 4: Determine P\&C factors' point deductions based on bridge condition: As shown in Table 2, each of the P\&C factors is classified into two or three levels that can help describe the condition of the bridge, and each level is assigned a specific number of points that will be deducted accordingly from the initial score.

Table 2. The levels corresponding to each $P \& C$ factor, and associated points $[5,40]$.

\begin{tabular}{|c|c|c|}
\hline Performance Factors & Levels Corresponding to Each Factor & Points Deducted \\
\hline \multirow{3}{*}{$\begin{array}{l}\text { Deck drainage system } \\
\text { and ponding }\end{array}$} & Water is allowed to sit on the surface and no drainage system & -10 \\
\hline & Minor ponding, but drainage system is not maintained & -5 \\
\hline & No problems noted & 0 \\
\hline \multirow{3}{*}{$\begin{array}{l}\text { Year of construction } \\
\text { or replacement } \\
\text { maintenance }\end{array}$} & More than 40 years old & -10 \\
\hline & From 40 to 15 years old & -5 \\
\hline & Less than 15 years old & 0 \\
\hline \multirow{3}{*}{$\begin{array}{l}\text { Protective layer over } \\
\text { concrete surface }\end{array}$} & No or poor sealer & -10 \\
\hline & Sealer with limited effectiveness & -5 \\
\hline & Well-maintained sealer & 0 \\
\hline \multirow{3}{*}{ Bridge skewness } & Skew more than $30^{\circ}$ & -10 \\
\hline & From $20-30^{\circ}$ & -5 \\
\hline & Less than $20^{\circ}$ & 0 \\
\hline \multirow{3}{*}{$\begin{array}{l}\text { Average daily truck } \\
\text { traffic (ADTT) }\end{array}$} & High $($ ADTT > 1000) & -10 \\
\hline & Moderate $(1000>$ ADTT > 100) & -5 \\
\hline & Minor $(100>$ ADTT $>15)$ & 0 \\
\hline \multirow{3}{*}{$\begin{array}{l}\text { Subjectivity to } \\
\text { overspray }\end{array}$} & Severe overspray & -10 \\
\hline & Moderate overspray & -5 \\
\hline & No overspray & 0 \\
\hline \multirow{2}{*}{ Reinforcement type } & Not epoxy-coated & -10 \\
\hline & Epoxy-coated & 0 \\
\hline
\end{tabular}


Table 2. Cont.

\begin{tabular}{|c|c|c|}
\hline Consequence Factors & Levels Corresponding to Each Factor & Points Deducted \\
\hline \multirow{3}{*}{$\begin{array}{l}\text { Damage to the top of } \\
\text { the bridge }\end{array}$} & $\begin{array}{l}\text { The bridge carries a high volume of traffic. Damage to the top of the bridge can } \\
\text { cause major traffic delays and accidents. }\end{array}$ & -10 \\
\hline & $\begin{array}{l}\text { The bridge carries a moderate volume of traffic. Damage to the top of the bridge } \\
\text { can cause moderate delays due to lane closures. }\end{array}$ & -5 \\
\hline & $\begin{array}{l}\text { The bridge carries a low volume of traffic. Damage to the top of the bridge will not } \\
\text { affect the serviceability of the bridge. }\end{array}$ & 0 \\
\hline \multirow{3}{*}{$\begin{array}{l}\text { Features under } \\
\text { the bridge }\end{array}$} & $\begin{array}{l}\text { Bridge crosses over a highway or a high-volume roadway such that any spalling } \\
\text { will cause major traffic delay, injures, or accidents. }\end{array}$ & -10 \\
\hline & $\begin{array}{l}\text { Bridge crosses over a moderate volume roadway, a lightly traveled waterway, or a } \\
\text { multi-path railroad. Spalling can cause moderate road delay or minor accidents. }\end{array}$ & -5 \\
\hline & Bridge crosses over non-navigable water or unused land. & 0 \\
\hline \multirow{3}{*}{ Structural capacity } & $\begin{array}{l}\text { The structural capacity is highly affected by the deterioration of this bridge } \\
\text { component, and damage can lead to bridge failure. }\end{array}$ & -10 \\
\hline & $\begin{array}{l}\text { The structural capacity will decrease and load posting or bridge closure might } \\
\text { be required. }\end{array}$ & -5 \\
\hline & $\begin{array}{c}\text { The structural capacity will be adequate without any effect on serviceability or } \\
\text { performance of the bridge. }\end{array}$ & 0 \\
\hline \multirow{3}{*}{ Alternative routes } & $\begin{array}{l}\text { There are no alternative routes. Therefore, any bridge closure will be a major } \\
\text { blockage on the bridge network. }\end{array}$ & -10 \\
\hline & There are some alternative routes, but still delays will happen. & -5 \\
\hline & There are many alternative routes the public can use. & 0 \\
\hline
\end{tabular}

In this study, the maximum number of points that can be deducted due to a single factor is 10 and the lowest is 0 . Therefore, in Step 3, when we were calculating the initial maximum score, we multiplied the number of factors by 10 , so that when we start deducting points in Step 5, we are starting at the highest possible score a bridge can achieve based on its current rating or condition. It should be noted that with a few adjustments, bridge owners can change the weight of each factor depending on its importance and can divide the factor into different levels.

Step 5: Deduct points from initial score: As the condition of the bridge worsens and the outcome of failure becomes more severe, more points are deducted from the initial score. For example, if a bridge did not have a drainage system and corrosion cracks on top of the bridge would cause major traffic delays, then according to the information in Table 2, 20 points will be deducted from the initial score assigned in Step 3. There should be a limit to the number of factors where a bridge can score a -10 or the number of points a bridge can lose before dropping to a lower category. Thus, when assigning the initial score (in Step 3) for a bridge with rating 6, a "3" was subtracted from the number of factors (see Table 1). This can help guarantee that a bridge losing more than 30 points (since the 3 is multiplied by 10) or, for example, scoring a -10 in more than three factors will not be considered in the high category. Bridge owners can assign other limits, such as changing the 3 to 4 or directly considering a bridge in the medium category if the bridge scored -10 in more than four factors.

Step 6: Rank the bridge from high to low and choose uncertainty thresholds: To select uncertainty thresholds for inspection planning, the scale shown in Figure 2 will be used. Based on the points deducted from the initial score and the calculated final score, the bridge will be ranked in one of the three categories (low/medium/high), and accordingly, the values of the uncertainty threshold $\mathrm{P}_{\text {th }}$ and $\sigma_{\text {th }}$ will be selected. Simply, if the bridge rank is low, then low threshold values $\left(\sigma_{\text {th }}{ }^{\text {low }} \& \mathrm{P}_{\text {th }}{ }^{\text {low }}\right)$ should be selected. 


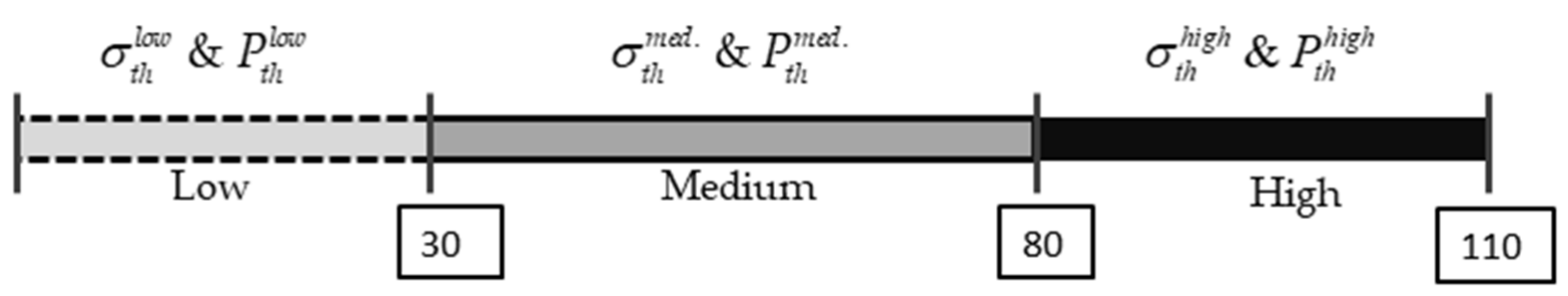

Figure 2. Scale for choosing the uncertainty threshold (the figure is not drawn to scale).

There are some recommendations a bridge inspection planner should consider when using the expert-based assessment procedure or the scale shown in Figure 2:

(1) If the score lands on a cutoff point (e.g., 80), the lower category controls.

(2) The upper bound of the high category should not exceed the maximum initial score which is equal to the maximum number of points that can be deducted.

(3) The upper bound of the medium category should equal the initial score assigned to a bridge with an NBI rating of 6 . It is risky to choose a high threshold for a bridge that was rated to be in a moderate condition (NBI rating of 6 or CS2), since high thresholds will lead to fewer inspections and a longer time interval between inspections.

(4) Bridge inspection planners can divide the scale in Figure 2 into more than three categories (i.e., low /medium/high) in order to cover a wider range of uncertainty thresholds and bridge conditions.

(5) An expert panel should be established to calibrate and decide on the values of the thresholds $P_{\text {th }}$ and $\sigma_{\text {th }}$. The panel should consist of employees with different responsibilities in the agency's bridge management department. Further explanation on how to establish starting threshold values (e.g., $\mathrm{P}_{\text {th }}^{\text {low }}=15 \%$ and $\sigma_{\text {th }}^{\text {low }}=2.30$ years) is shown in the example application.

Finally, once the values of $\sigma_{Y}$ and $F(t)$ exceed or equal the chosen $\sigma_{\text {th }}$ and $P_{\text {th }}$, an inspection should be considered.

\subsection{Choosing Inspection Method}

While the inspection time is selected to prevent uncertainty in the bridge condition from exceeding an acceptable value, the inspection method is selected such that the information provided by the inspection can be used to most effectively reduce the uncertainty in the condition of the bridge element when the inspection is conducted. Selection of the inspection method is complicated by many factors influencing the effectiveness. One factor affecting the utility of different inspection techniques is the stage of the bridge's service life; depending on the state of deterioration, some techniques may be useless. Accuracy of the inspection technique is another important factor; the level of uncertainty in the bridge condition can only be reduced if the inspection results are trustworthy. However, improving the quality of the inspection technique might lead to higher inspection costs; therefore, inspection techniques must be strategically decided upon. Nondestructive evaluation (NDE) techniques are a valuable tool for bridge inspection as they can provide data to quantitatively assess the physical parameters that represent different damage mechanisms (e.g., cover thickness, chloride content, corrosion rate, and crack width) [10]. These values can be used to evaluate the bridge condition directly or to develop and improve predictions of deterioration models.

To select a suitable NDE method, a bridge inspector should start by identifying the parameters in the deterioration model that can be efficiently measured and for which updated values improve the model prediction. These parameters can be identified by conducting a sensitivity analysis and finding the parameters that have the highest impact on the deterioration model prediction [46]. Once parameters to measure have been identified, there are a variety of resources to help find relevant NDE methods and information about the methods $[10,47]$. However, all NDE methods are accompanied with uncertainties in 
measurements and difficulties in implementation onsite [48]. Therefore, quantifying the accuracy of the inspection technique and incorporating the uncertainty of different inspection techniques in the selection process is a primary step in the framework, as described in the following sections.

\subsubsection{Accuracy of Inspection Methods and Data Obtained during Inspections}

The accuracy of an inspection technique can be expressed as the relation between the measured defect and the actual defect size [49]. The detected structure defect is usually subject to inaccuracies and noise during inspection. Herein, the accuracy of an NDE method will be mathematically formulated using the following linear regression analysis, Equation (3) [49]:

$$
\mathrm{Y}\left(\mathrm{t}_{\text {Ins }}\right)=\psi_{1}+\psi_{2} \mathrm{a}_{\mathrm{M}}\left(\mathrm{t}_{\text {Ins }}\right)+\mathrm{e}
$$

where $Y\left(t_{I n s}\right)$ is the actual defect size at the inspection time $t_{I n s}, a_{M}\left(t_{I n s}\right)$ is the measured defect during inspection, $\psi_{1}$ and $\psi_{2}$ are regression parameters that need to be calibrated according to the inspection technique (i.e., NDE method), and e is the measurement error described as a Gaussian random variable with a zero mean and a standard deviation $\sigma_{\mathrm{e}}$ that varies according to the accuracy of the inspection and the geometry of the analyzed element [49]. Overall, Equation (3) can provide a probabilistic representation of the actual defect $Y\left(t_{I n s}\right)$, which will follow a Gaussian distribution with a mean $\psi_{1}+\psi_{2} a_{M}\left(t_{I n s}\right)$ and a standard deviation $\sigma_{e}$ (i.e., $\left.\mathrm{Y}\left(\mathrm{t}_{\mathrm{Ins}}\right) \sim \mathrm{N}\left(\psi_{1}+\psi_{2} \mathrm{a}_{\mathrm{M}}\left(\mathrm{t}_{\mathrm{Ins}}\right), \sigma_{\mathrm{e}}\right)\right)$ [42]. The higher the accuracy of an NDE, the lower $\sigma_{e}$ will be, which will provide measurements closer to the actual deterioration process, providing a higher reduction in the uncertainty and enhancing the model prediction [39].

\subsubsection{Incorporating Inspection Results Using Bayesian Updating}

To reduce the uncertainty in the deterioration model prediction, Bayesian updating can be used to update the prediction model parameters $\theta$ by combining the new inspection data with the prior or existing information [42]. The posterior or updated distributions for the probabilistic model parameters $\theta$ can be estimated using Equation (4) [50]:

$$
\mathrm{P}\left(\theta \mid \mathrm{a}_{\mathrm{M}}\left(\mathrm{t}_{\text {Ins }}\right)\right)=\frac{\mathrm{L}\left(\mathrm{a}_{\mathrm{M}}\left(\mathrm{t}_{\text {Ins }}\right) \mid \theta\right) \mathrm{P}(\theta)}{\int \mathrm{L}\left(\mathrm{a}_{\mathrm{M}}\left(\mathrm{t}_{\text {Ins }}\right) \mid \theta\right) \mathrm{P}(\theta) \mathrm{d} \theta}
$$

where $\mathrm{P}\left(\theta \mid \mathrm{a}_{\mathrm{M}}\left(\mathrm{t}_{\mathrm{Ins}}\right)\right)$ is the posterior distribution of a model parameter $\theta, \mathrm{a}_{\mathrm{M}}\left(\mathrm{t}_{\mathrm{Ins}}\right)$ is the measured defect during inspection, $\mathrm{L}\left(\mathrm{a}_{\mathrm{M}}\left(\mathrm{t}_{\mathrm{Ins}}\right) \mid \theta\right)$ is the likelihood function of measuring $\mathrm{a}_{\mathrm{M}}\left(\mathrm{t}_{\mathrm{Ins}}\right)$ for a given $\theta$, and $\mathrm{P}(\theta)$ is the prior distribution of $\theta$. Further, if $\mathrm{a}_{\mathrm{DM}}\left(\mathrm{t}_{\mathrm{Ins}}\right)$ is the prediction of the deterioration model using $\theta$, then based on the inspection accuracy represented in Equation (3), the likelihood function can be formulated as Equation (5) [42]:

$$
\mathrm{L}\left(\mathrm{a}_{\mathrm{M}}\left(\mathrm{t}_{\text {Ins }}\right) \mid \theta\right)=\prod_{\mathrm{i}=1}^{\mathrm{n}_{\text {Ins }}}\left\{\phi\left[\frac{\mathrm{a}_{\mathrm{DM}}\left(\mathrm{t}_{\text {Ins }}\right)-\psi_{1}-\psi_{2} \cdot \mathrm{a}_{\mathrm{M}}\left(\mathrm{t}_{\text {Ins }}\right)}{\sigma_{\mathrm{e}}}\right]\right\}
$$

If a number of measurements or inspections $\mathrm{n}_{\text {Ins }}$ are conducted using the same technique, the likelihood function can be updated as the product of the PDF for each inspection measurement, assuming independence between the measurements.

When the framework is applied for the first time before the TTT for a given bridge, it is very important to note that until this stage of the proposed framework, an NDE inspection has not been performed at $t_{I n s}$ and the actual inspection results $a_{M}\left(t_{I n s}\right)$ have not yet been obtained. Thus, to use Bayesian updating in selecting the suitable inspection method at $t_{\text {Ins }}$, a pre-posterior analysis can be conducted, by (1) assuming different values of $\mathrm{a}_{\mathrm{M}}\left(\mathrm{t}_{\mathrm{Ins}}\right)$ and different inspection scenarios (i.e., NDE methods); (2) establishing the posterior values for each different inspection outcome; and (3) updating the information regarding the condition of the bridge and TTT, according to each assumed or available 
inspection scenario. The standard deviation $\sigma_{\mathrm{TTT}}$ and $\mathrm{COV}_{\mathrm{TTT}}$ will be used to quantify uncertainty in the estimated TTT and the reduction achieved by the NDE candidates.

Based on the results of the pre-posterior analysis, the candidate NDE methods or NDE consultants will be compared, and if the inspection cost is not a constraint, then the candidate that can reduce the uncertainty regarding the TTT the most will be selected. In practice, the inspection cost will always be a burden, and in some scenarios, the most accurate inspection method will not be cost-effective compared to other inspection techniques, especially in the short run. However, the bridge inspection planner may find that an expensive inspection method might be worthwhile if the whole bridge life cycle is considered, since a more accurate technique will lead to fewer inspections as will be demonstrated in the application example. If multiple inspection methods satisfy the required criteria, the bridge inspector can choose the appropriate inspection method after considering the cost of the inspection and the availability of the inspection technique.

Finally, after performing the actual inspection, the inspection results will be used to update the model parameters using Bayesian updating, and the posterior values will be used in the next planning cycle to choose the following inspection time and technique.

\section{Example Application of the Framework}

In this example, the uncertainty-based inspection framework will be applied on an existing bridge in Colorado. The example will be divided in two main parts. In the first part, the bridge is assumed to be relatively new, with just two years of operating history. To demonstrate the capabilities of the framework, only one deterioration process will be considered in this part. Then, in the second part of the example, it will be assumed that the bridge has been operating for more than 15 years and corrosion is active, and two deterioration mechanisms will be considered in choosing the inspection time: pitting corrosion depth and crack growth.

\subsection{Description of Bridge}

E-17-HS is a four-span bridge in Colorado, and according to the information provided by $[21,51,52]$, the bridge is a two-lane bridge crossing over interstate highway 25 at 160th Avenue. Figure 3 shows a schematic drawing of the deck cross-section. The thickness of the concrete slab is $18 \mathrm{~cm}$ and the concrete cover over the top slab reinforcement is $30 \mathrm{~mm}$. The deck is supported by four RC beams in the end spans and steel girders in the intermediate spans. The concrete deck in the end spans is $11.3 \mathrm{~m}$ long and $10.40 \mathrm{~m}$ wide. The spacing between the RC girders is $2.65 \mathrm{~m}$ and the depth and width of the RC girders are almost 66 and $40 \mathrm{~cm}$, respectively. This example focuses on corrosion of the top slab reinforcement, where maximum negative moments will occur due to transverse loads on the bridge deck.

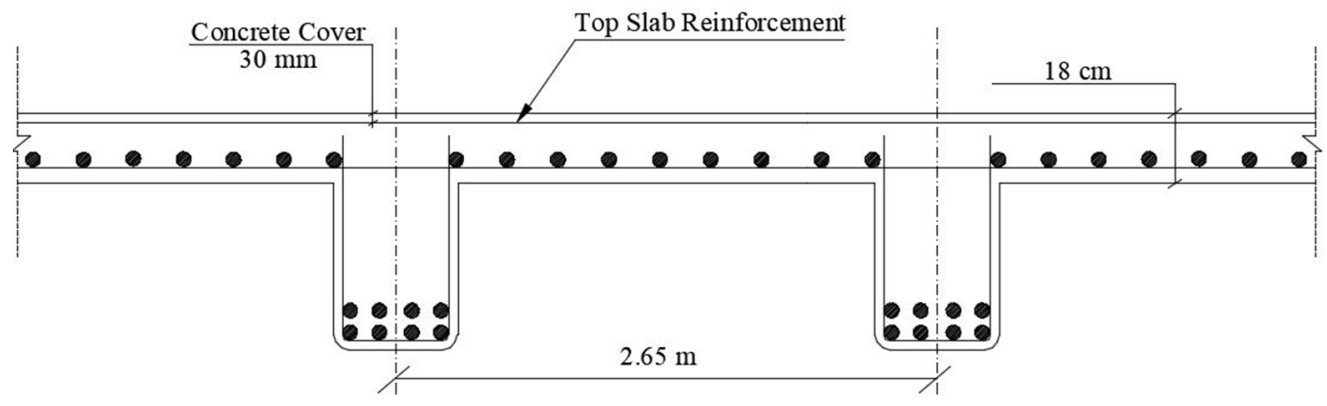

Figure 3. Schematic drawing for the cross-section of the reinforced concrete (RC) deck.

\subsection{Part 1: Applying the Proposed Framework on a New Bridge}

Applying the proposed framework to a new bridge begins in year two of the bridge service life. At this time, a visual inspection has been conducted to make sure everything is operating well and according to design. The time to transition (TTT) in Part 1 considers only 
the first corrosion deterioration stage in the RC deck service life and will be expressed as the time when corrosion initiates in the top reinforcement. Corrosion is assumed to initiate when the chloride concentration at the rebar level reaches $0.04 \mathrm{~g} / \mathrm{mm}^{3}$ [21]. The TTT can be considered by a bridge inspection planner as the appropriate time to apply a preserving maintenance (e.g., adding a sealant to the concrete surface) to delay corrosion propagation and help avoid a late and costly maintenance action (e.g., removing the whole top cover of the concrete surface). To clearly demonstrate how the framework can be implemented, the planning process will be represented as a series of tasks the bridge inspection planner is expected to follow.

\subsubsection{Task 1: Year 2, Selecting Suitable Deterioration Model}

Deterioration models for corrosion meeting the requirements of Section 3.2.1 have been selected for Parts 1 and 2 of this example and are detailed in Appendix A. The prediction model shown in Equation (A1) was selected for Part 1 of the example to predict the TTT (corrosion initiation time) and to propagate uncertainty in the deterioration process. This mechanistic model can be updated by measuring some of its parameters onsite using well-established NDE methods as discussed subsequently. In addition to selecting a model, appropriate model parameters must be established. The values of the parameters can be obtained from previous inspections, archived data for similar bridges, or from the available literature. The values and probabilistic descriptions of the parameters in Equation (A1) used for this example are summarized in Table 3.

Table 3. Values and probabilistic descriptors of parameters used in Equation (A1).

\begin{tabular}{cccccc}
\hline Variable & Notation (Units) & Mean & COV & Distribution & References \\
\hline Cover & $\mathrm{x}(\mathrm{mm})$ & 30 & 0.2 & Lognormal & {$[52]$} \\
\hline Surface chloride content & $\mathrm{C}_{0}\left(\mathrm{~g} / \mathrm{mm}^{3}\right)$ & 0.15 & 0.1 & Lognormal & {$[21]$} \\
\hline Diffusion coefficient & $\mathrm{D}_{\mathrm{c}}\left(\mathrm{mm}^{2} /\right.$ year $)$ & 26.68 & 0.1 & Lognormal & {$[51]$} \\
\hline Critical chloride content & $\mathrm{C}_{\mathrm{th}}\left(\mathrm{g} / \mathrm{mm}^{3}\right)$ & 0.04 & 0.14 & Lognormal & {$[21,53]$} \\
\hline
\end{tabular}

4.2.2. Task 2: Year 2, Predicting the TTT and Developing the Two Criteria for Choosing Next Inspection Time

As mentioned earlier in Section 3.2.2., there are two criteria used in the framework to select the next inspection time. The first criterion is based on the uncertainty level in the predicted bridge condition before the TTT and the second is based on the probability of transitioning to another stage in the bridge service life.

For the first criterion, the deterioration model in Equation (A1) and Monte Carlo simulation (sample size 100,000) were used to predict the corrosion initiation time (i.e., TTT, when chlorides reach $0.040 \mathrm{~g} / \mathrm{mm}^{3}$ at the rebar level). Then, to propagate uncertainty in the condition of the bridge before the TTT, the expected time $\mathrm{E}(\mathrm{t})$ required to reach a specified chloride concentration $\mathrm{C}_{\mathrm{ch}}$ at the rebar level and the corresponding standard deviation $\sigma_{Y}$ were estimated. PDFs for the corrosion initiation time and time to reach a certain $\mathrm{C}_{\mathrm{ch}}$, ranging from $0.010 \mathrm{~g} / \mathrm{mm}^{3}$ to $0.040 \mathrm{~g} / \mathrm{mm}^{3}$ with an increment of $0.005 \mathrm{~g} / \mathrm{mm}^{3}$, are shown in Figure 4. The PDFs in Figure 4 show that as the target chloride concentration and thus the length of simulation increase, there is a greater spread in the distribution, indicating less certainty in the prediction model results.

From Figure 4 , it can be seen that the expected corrosion initiation time $\mu_{\mathrm{TTT}}$ (expected TTT) and the corresponding standard deviation $\sigma_{\text {TTT }}$ are 15.50 and 7.50 years, respectively. Table 4 shows the $\mathrm{E}(\mathrm{t})$ to reach a specified chloride concentration at the rebar level and the corresponding $\sigma_{Y}$. For example, at a mean time of 9.50 years, the $C_{c h}$ at the rebar level is anticipated to equal $0.025 \mathrm{~g} / \mathrm{mm}^{3}$ and the $\sigma_{Y}$ is expected to reach 4.50 years. 


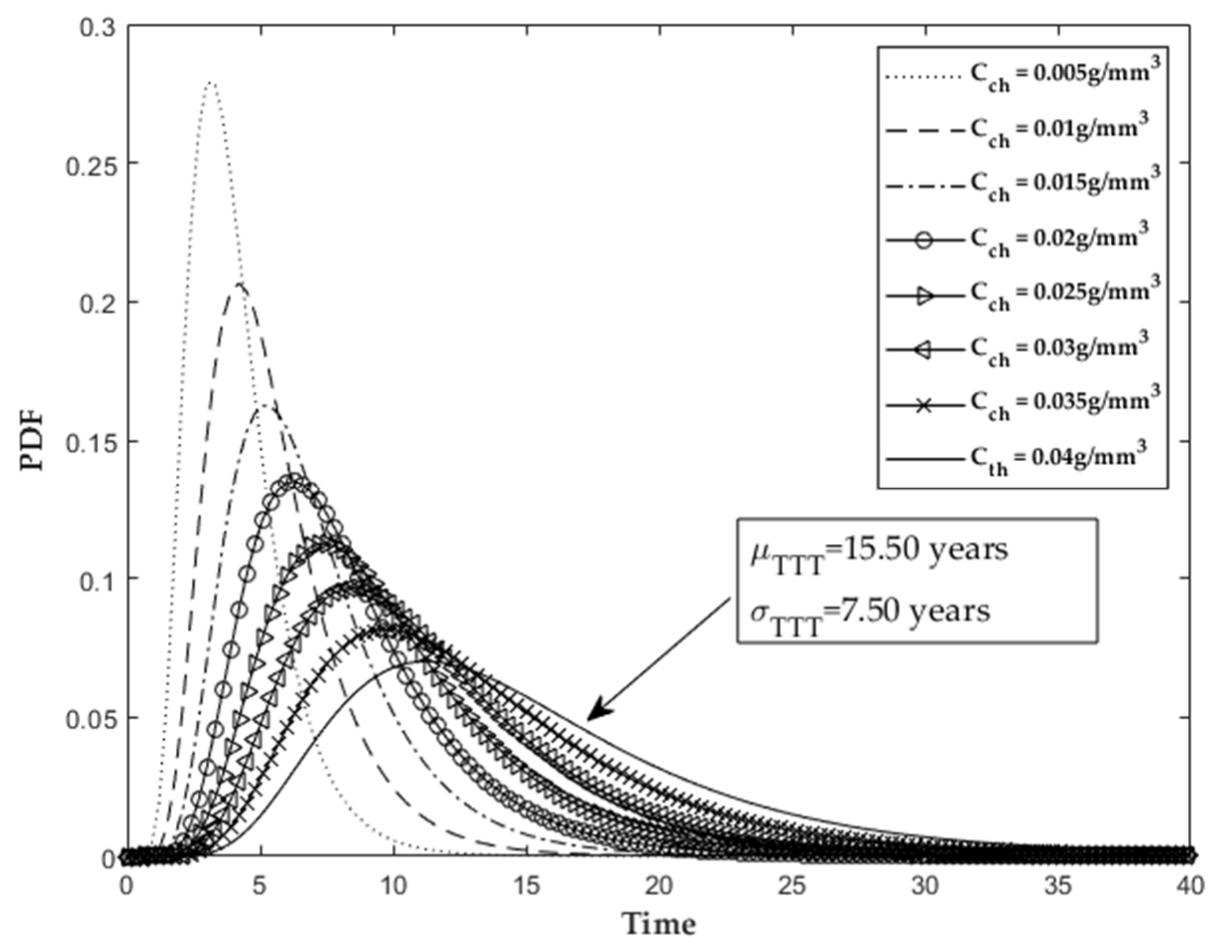

Figure 4. Probability distribution functions (PDFs) for corrosion initiation time and time to reach a certain $C_{c h}$ at the rebar level.

Table 4. Expected time to reach specified chloride concentration at the rebar level and corresponding standard deviation.

\begin{tabular}{ccc}
\hline $\mathrm{C}_{\mathrm{ch}}\left(\mathrm{g} / \mathrm{mm}^{\mathbf{3}}\right)$ & $\mathrm{E}[\mathrm{t}]$ (Years) & $\sigma_{\mathbf{Y}}($ Years$)$ \\
\hline 0.005 & 4.00 & 2.00 \\
\hline 0.010 & 5.50 & 2.50 \\
\hline 0.015 & 6.50 & 3.50 \\
\hline 0.020 & 8.00 & 4.00 \\
\hline 0.025 & 9.50 & 4.50 \\
\hline 0.030 & 11.00 & 5.00 \\
\hline 0.035 & 13.00 & 6.00 \\
\hline $0.040=\mathrm{C}_{\text {th }}$ & $15.50=\mu_{\mathrm{TTT}}$ & $7.50=\sigma_{\mathrm{TTT}}$ \\
\hline
\end{tabular}

For the second criterion, to calculate the probability of corrosion initiation (i.e., reaching the TTT) at different time periods, the cumulative probability of transition $\mathrm{F}(\mathrm{t})$ (i.e., lifetime function) was obtained from the conducted Monte Carlo simulation as shown in Figure 5. For example, according to the $\mathrm{F}(\mathrm{t})$, there is almost a $22 \%$ chance that the TTT for the concrete deck will be at year 10 (i.e., $22 \%$ probability that corrosion will initiate at year 10).

According to the obtained cumulative probability of transition $\mathrm{F}(\mathrm{t})$ and the calculated $\sigma_{Y}$, the first bridge inspection $t_{I n s, 1}$ should be considered whenever $\sigma_{Y}$ or $F(t)$ exceed their corresponding uncertainty thresholds, $\sigma_{\text {th }}$ and $\mathrm{P}_{\text {th }}$, respectively. 


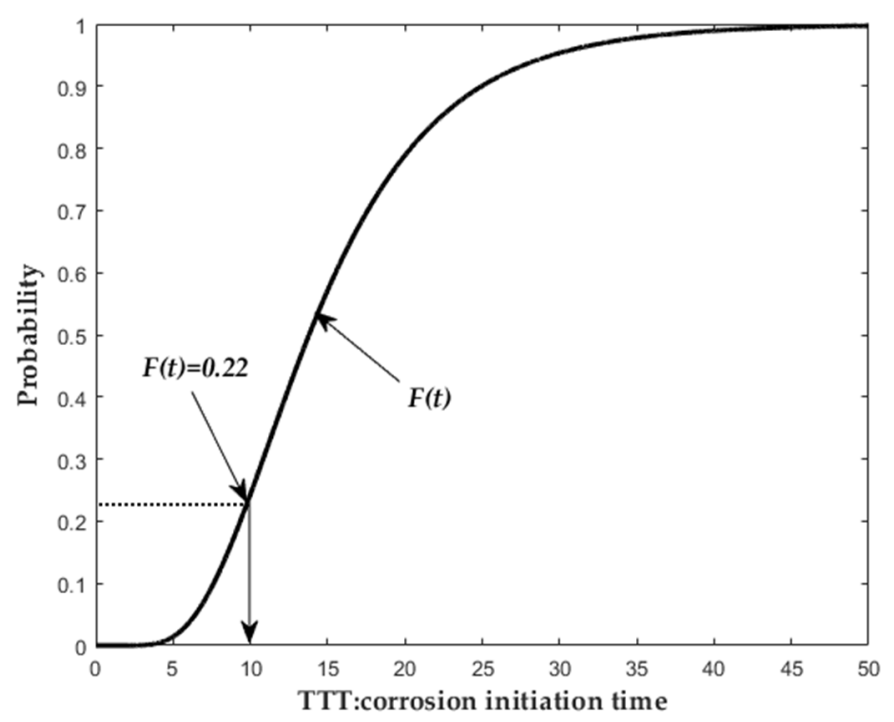

Figure 5. Cumulative probability of transition.

\subsubsection{Task 3: Year 2, Determining the Uncertainty Thresholds $\sigma_{\text {th }}$ and $P_{\text {th }}$}

To determine the uncertainty thresholds, the expert-based assessment process (described in Section 3.2.3.) will be conducted in this section. As discussed earlier, the damage considered here is corrosion of reinforced concrete decks, and the total number of performance and consequence factors ( $\mathrm{P} \& \mathrm{C}$ factors) considered is eleven (See Table 2). The bridge in this part of the example is considered new with an NBI condition rating above 7 . Therefore, based on the scoring system described in Table 1, the initial maximum score of the E-17-HS bridge deck is 110 .

Table 5 shows the points that will be deducted from the initial maximum score based on the information available on the bridge E-17-HS in [21,51,52], the levels and description of each performance and consequence factor provided in Table 2, and rational assumptions.

According to the points assigned in Table 5, the total number of points that will be deducted from the score of 110 is 45 points, resulting in a final score equal to 65 . According to the scale shown in Figure 2, the concrete deck will be considered in the medium category and medium uncertainty thresholds should be used. This shows that although the bridge had a rating above 7 and is new, it still was not considered in the high category due to the factors that can affect its performance and the risks of the failure outcomes.

If the uncertainty-based inspection framework had been used in the past, the agency could use or perhaps update existing threshold values. In this case, since it is assumed that this is the first time implementing the uncertainty-based inspection framework, the agency will need to establish threshold values to assign to each inspection category. Threshold values used for this example to represent low, medium, and high uncertainty thresholds will be those shown in Table 6. It should be noted that these values are not fixed and can be changed. Moreover, the number of categories can be increased as discussed earlier, but here, only three categories are used for simplicity (low/medium/high). The threshold values shown in Table 6 are only for demonstration purposes, and when choosing the values, the aim was to: (1) show that the two criteria can yield different inspection times, (2) avoid having a threshold in a lower category yielding an inspection time after any threshold in the better category, for example, if $\mathrm{P}_{\text {th }}$ was $25 \%$ in the low category, it would have required an inspection (i.e., around year 10.5) after the inspection time required by the $\sigma_{\text {th }}=0.5 \sigma_{\text {TTT }}$ (i.e., at year 8) in the medium category, and (3) avoid performing inspections after the expected TTT, for example, the $\sigma_{\text {th }}$ was considered as a fraction from the $\sigma_{\text {TTT }}=7.5 y e a r s$, and this will help assure that when $\sigma_{Y}$ exceeds $\sigma_{\text {th }}$ (i.e., an inspection should be considered), its value will still be less than $\sigma_{\text {TTT }}$ and inspections will be conducted before the TTT. Based on these concepts and others, agencies can calibrate their inspection thresholds to provide 
inspection intervals that satisfy expert judgement and guarantee the safety of the bridge, and once the thresholds are set, they can be used on many bridges.

Table 5. Points that will be deducted from initial score based on the P\&C factors.

\begin{tabular}{|c|c|c|}
\hline Performance Factors & E-17-HS Condition & Points Deducted \\
\hline $\begin{array}{l}\text { Deck drainage system } \\
\text { and ponding }\end{array}$ & The deck does not have a drainage system & -10 \\
\hline $\begin{array}{l}\text { Year of construction or } \\
\text { replacement maintenance }\end{array}$ & Bridge is assumed new and has been operating for two years only & 0 \\
\hline $\begin{array}{l}\text { Protective layer over } \\
\text { concrete surface }\end{array}$ & The deck has an asphalt overlay but with limited effectiveness & -5 \\
\hline Bridge skewness & The bridge is not skew & 0 \\
\hline $\begin{array}{l}\text { Average daily truck } \\
\text { traffic (ADTT) }\end{array}$ & This bridge only has an average of 5 heavy trucks per day & 0 \\
\hline Subjectivity to overspray & $\begin{array}{l}\text { The bridge crosses over a roadway exposed to deicing salts and has a clearance } \\
\text { of } 5 \mathrm{~m} \text { which makes it subject to moderate overspray }\end{array}$ & -5 \\
\hline Reinforcement type & Uncoated carbon steel bars & -10 \\
\hline Consequence Factors & E-17-HS Condition & Points Deducted \\
\hline $\begin{array}{l}\text { Damage to the top of } \\
\text { the bridge }\end{array}$ & $\begin{array}{l}\text { Bridge E-17-HS has a moderate average daily traffic ranging from } \\
600 \text { to } 1000 \text { vehicles per day and any damage to the top of the bridge or closing } \\
\text { the bridge for long durations of maintenance can cause moderate delays }\end{array}$ & -5 \\
\hline Features under the bridge & $\begin{array}{l}\text { The bridge crosses over a highway (Interstate-25) and any spalling of } \\
\text { concrete due to corrosion could cause major traffic delays and may cause } \\
\text { accidents or injuries }\end{array}$ & -10 \\
\hline Structural capacity & $\begin{array}{l}\text { The initiation of corrosion will have almost no effect on the capacity of the } \\
\text { steel rebars, structural safety, or serviceability since cracking has not yet } \\
\text { started and the area of the steel rebars has not been affected due to corrosion }\end{array}$ & 0 \\
\hline Alternative routes & $\begin{array}{l}\text { There are two main alternative routes that the public can use if the bridge } \\
\text { was closed, in order to avoid public delays as much as possible }\end{array}$ & 0 \\
\hline
\end{tabular}

Table 6. Values of uncertainty thresholds to be embedded from Figure 2's scale.

\begin{tabular}{ccc}
\hline Uncertainty Thresholds & \multicolumn{1}{c}{$\boldsymbol{\sigma}_{\text {th }}$} & $\mathbf{P}_{\text {th }}$ \\
\hline Low & $0.3 \sigma_{\text {TTT }}=2.30$ years & $15 \%$ \\
\hline Medium & $0.5 \sigma_{\text {TTT }}=3.75$ years & $30 \%$ \\
\hline High & $0.7 \sigma_{\text {TTT }}=5.25$ years & $40 \%$ \\
\hline
\end{tabular}

In short, a bridge inspection should be considered when $\sigma_{Y}$ and $F(t)$ exceed or equal 3.75 years or $30 \%$, respectively. According to the first uncertainty threshold $\sigma_{\text {th }}$ and the values of $\sigma_{Y}$ at different times in Table 4, the first NDE bridge inspection $t_{\text {Ins }, 1}^{\sigma}$ should be considered at year 8 (i.e., 6 years from year 2), when the $\sigma_{Y}$ will equal 4 years, exceeding the 3.75 years threshold (i.e., $\sigma_{Y}>\sigma_{\text {th }}$ ). Based on the second criterion or threshold $P_{\text {th }}$ and the obtained cumulative probability of transition in Figure 5, the value of $\mathrm{F}(\mathrm{t})$ will exceed $30 \%$ at almost year 11 (i.e., $\mathrm{t}_{\mathrm{Ins}, 1}^{\mathrm{P}}=11$ years). Thus, based on the proposed procedure, the first NDE inspection $t_{I n s, 1}$ will be conducted at year 8 (i.e., $t_{I n s, 1}$ is the minimum of both $t_{\text {Ins, } 1}^{\sigma}$ and $\mathrm{t}_{\text {Ins,1 }}^{\mathrm{P}}$ ).

\subsubsection{Task 4: Choosing NDE Inspection Method for $\mathrm{t}_{\text {Ins, } 1}=8$ years}

The deterioration model in Equation (A1) can be updated by measuring the surface chloride content $\mathrm{C}_{0}$ and/or the concrete cover using NDE methods such as the chloride ion penetration test (CIP) or a cover meter (CM), respectively [54] (the most informative 
approach would be to measure the chloride concentration at the rebar level, but this would involve a destructive core test). Equation (3) will be used to analyze the effect of the NDE accuracy on reducing the uncertainty in the predicted TTT, where $\mathrm{a}_{M}$ represents the measured surface chloride concentration or concrete cover, and $Y\left(t_{I n s}\right)$ is the real value of the parameters at the time of inspection which is represented as a Gaussian random variable. Agencies may conduct their own nondestructive tests, and in this example, it is assumed that five NDE consultants have offered their services, as shown in Table 7, to the bridge agency. The bridge inspection planner is required to select one of these consultants to conduct the inspection using the proposed framework. All five consultants will use a CIP test with different accuracies and only consultant 5 will also use a CM during the inspection at year 8 to make sure the cover is adequate. The concrete cover was added to the inspection options to analyze its effect on the model prediction and to see the effect of measuring more than one parameter on the uncertainty level.

Table 7. Accuracy details of NDE methods proposed by of the five different consultants.

\begin{tabular}{|c|c|c|c|c|c|}
\hline \multirow{2}{*}{\multicolumn{2}{|c|}{$\begin{array}{l}\text { Consultants and NDE } \\
\text { Methods Used }\end{array}$}} & \multirow{2}{*}{ Description of Inspection Quality } & \multicolumn{3}{|c|}{$\mathrm{Y}(8 \mathrm{yrs}) \sim \mathrm{N}\left(\psi_{1}+\psi_{2} \mathrm{a}_{\mathrm{M}}(8 \mathrm{yrs}), \sigma_{\mathrm{e}}\right)$} \\
\hline & & & $\psi_{1}$ & $\psi_{2}$ & $\sigma_{\mathrm{e}}$ \\
\hline \multicolumn{2}{|c|}{ Consultant 1: CIP } & Unbiased, with accuracy $\pm 10 \%$ out of the measured $C_{0}$ & 0 & 1 & $0.1 \mathrm{a}_{\mathrm{M}}$ \\
\hline \multicolumn{2}{|c|}{ Consultant 2: CIP } & Unbiased, with accuracy $\pm 25 \%$ out of the measured $C_{0}$ & 0 & 1 & $0.25 \mathrm{a}_{\mathrm{M}}$ \\
\hline \multicolumn{2}{|c|}{ Consultant 3: CIP } & $\begin{array}{l}\text { Biased (real value will be higher than measurement), } \\
\text { with accuracy } \pm 10 \% \text { out of the measured } C_{0}\end{array}$ & 0 & 1.2 & $0.1 \mathrm{a}_{\mathrm{M}}$ \\
\hline \multicolumn{2}{|c|}{ Consultant 4: CIP } & $\begin{array}{l}\text { Biased (real value will be lower than measurement), } \\
\text { with accuracy } \pm 10 \% \text { out of the measured } C_{0}\end{array}$ & 0 & 0.8 & $0.1 \mathrm{a}_{\mathrm{M}}$ \\
\hline \multirow[b]{2}{*}{ Consultant 5: } & $\mathrm{CIP}$ & Unbiased, with accuracy $\pm 25 \%$ out of the measured $C_{0}$ & 0 & 1 & $0.25 \mathrm{a}_{\mathrm{M}}$ \\
\hline & $\mathrm{CM}$ & $\begin{array}{c}\text { Unbiased, with accuracy } \pm 15 \% \text { out of the measured } \\
\text { concrete cover. }\end{array}$ & 0 & 1 & $0.15 \mathrm{a}_{\mathrm{M}}^{\text {Cover }}$ \\
\hline
\end{tabular}

Table 7 shows the difference in the accuracy of the consultants and which consultants are expected to have biased results and require calibration. For example, for consultant 1 , it is assumed that the inspection will be unbiased and have an accuracy of $\pm 10 \%$ (i.e., $\sigma_{\mathrm{e}}=0.1 \mathrm{a}_{\mathrm{M}}$ ) out of the measured $\mathrm{C}_{0}$, compared to the NDE inspections conducted by consultants 3 and 4, where biased results are expected (i.e., calibrated using the regression line slope $\psi_{2}$ ). Information about the accuracies of the CIP test and the cover meter can be found in $[42,48]$.

Since only a visual inspection has been completed at this point, to choose the appropriate consultant and to conduct a pre-posterior analysis, it is assumed that the measured concrete cover will be $30 \mathrm{~mm}$, the same as the prior (i.e., $\mathrm{a}_{\mathrm{M}}^{\text {Cover }}=30 \mathrm{~mm}$ ), while the measured $C_{0}$ will be $0.3 \mathrm{~g} / \mathrm{mm}^{3}$ (i.e., $\mathrm{a}_{\mathrm{M}}=0.3 \mathrm{~g} / \mathrm{mm}^{3}$ ), which is double the prior assumed value used to begin predictions (see Table 3 ). This higher $C_{0}$ value was rationally assumed because at year 8 , the bridge would have been exposed to several deicing cycles and traffic splashes from the highway under the bridge, increasing the $\mathrm{C}_{0}$ while not having an efficient drainage system. As the $\mathrm{C}_{0}$ increases, the corrosion rate increases and the TTT decreases, meaning there may be less time for preventative maintenance. Further, this will be the first inspection based on the deterioration model before model accuracy in representing the real bridge condition has been verified. Assuming the condition will be worse than expected is a conservative approach. These assumed values could also be obtained either from prediction models that predict the future values of this specific parameter or from inspection reports of bridges that have similar properties. Using the parameters for $\psi_{1}, \psi_{2}$, and $\sigma_{\mathrm{e}}$, the probabilistic values of $\mathrm{Y}$ were established as shown in Table 8, based on the accuracy of each consultant and the assumed inspection results. These values will be used as the likelihood function in the Bayesian updating process. 
Table 8. Likelihood functions obtained based on assumed inspection values and consultants' accuracy.

\begin{tabular}{|c|c|c|}
\hline \multicolumn{2}{|c|}{ Consultants } & $Y\left(t_{\text {Insp }}\right) \sim N\left(\psi_{1}+\psi_{2} a_{M}\left(t_{I n s p}\right), \sigma_{e}\right)$ \\
\hline \multicolumn{2}{|c|}{ Consultant 1: CIP } & $\mathrm{Y}(8 \mathrm{yrs}) \sim \mathrm{N}\left(0.3 \mathrm{~g} / \mathrm{mm}^{3}, 0.03 \mathrm{~g} / \mathrm{mm}^{3}\right)$ \\
\hline \multicolumn{2}{|c|}{ Consultant 2: CIP } & $\mathrm{Y}(8 \mathrm{yrs}) \sim \mathrm{N}\left(0.3 \mathrm{~g} / \mathrm{mm}^{3}, 0.075 \mathrm{~g} / \mathrm{mm}^{3}\right)$ \\
\hline \multicolumn{2}{|c|}{ Consultant 3: CIP } & $\mathrm{Y}(8 \mathrm{yrs}) \sim \mathrm{N}\left(0.36 \mathrm{~g} / \mathrm{mm}^{3}, 0.03 \mathrm{~g} / \mathrm{mm}^{3}\right)$ \\
\hline \multicolumn{2}{|c|}{ Consultant 4: CIP } & $\mathrm{Y}(8 \mathrm{yrs}) \sim \mathrm{N}\left(0.24 \mathrm{~g} / \mathrm{mm}^{3}, 0.03 \mathrm{~g} / \mathrm{mm}^{3}\right)$. \\
\hline \multirow{2}{*}{ Consultant 5: } & CIP & $\mathrm{Y}(8 \mathrm{yrs}) \sim \mathrm{N}\left(0.3 \mathrm{~g} / \mathrm{mm}^{3}, 0.075 \mathrm{~g} / \mathrm{mm}^{3}\right)$ \\
\hline & $\mathrm{CM}$ & $\mathrm{Y}(8 \mathrm{yrs}) \sim \mathrm{N}(30 \mathrm{~mm}, 4.5 \mathrm{~mm})$ \\
\hline
\end{tabular}

Table 9 summarizes the results of the pre-posterior analysis and the calculated posterior values (i.e., the mean $\mu_{\mathrm{P}}$ and standard deviation $\sigma_{\mathrm{P}}$ ) for the $\mathrm{C}_{0}$ and concrete cover associated with the accuracy of each NDE consultant. The posterior values were used as the new inputs for the deterioration model Equation (A1) to obtain the expected TTT and reduction in the uncertainty level (i.e., $\sigma_{\text {TTT }}$ and $\mathrm{COV}_{\text {TTT }}$ ) associated with each consultant.

Table 9. Pre-posterior analysis for choosing inspection method and corresponding expected time to transition (TTT).

\begin{tabular}{|c|c|c|c|c|c|c|}
\hline \multirow{2}{*}{\multicolumn{2}{|c|}{ Consultants }} & \multicolumn{2}{|c|}{$\begin{array}{c}\text { Posterior Values of Measured } \\
\text { Parameters }\end{array}$} & \multirow[t]{2}{*}{$\mu_{\text {TTT }}$ (Years) } & \multirow[t]{2}{*}{$\sigma_{\mathrm{TTT}}($ Years) } & \multirow[t]{2}{*}{$\mathrm{COV}_{\text {TTT }}$} \\
\hline & & $\mu_{P}$ & $\sigma_{P}$ & & & \\
\hline \multicolumn{2}{|c|}{ Consultant 1 (Unbiased-accuracy 10\%) } & $0.181 \mathrm{~g} / \mathrm{mm}^{3}$ & $0.0134 \mathrm{~g} / \mathrm{mm}^{3}$ & 12.50 & 5.00 & $40 \%$ \\
\hline \multicolumn{2}{|c|}{ Consultant 2 (Unbiased-accuracy 25\%) } & $0.156 \mathrm{~g} / \mathrm{mm}^{3}$ & $0.0147 \mathrm{~g} / \mathrm{mm}^{3}$ & 14.50 & 6.50 & $45 \%$ \\
\hline \multicolumn{2}{|c|}{ Consultant 3 (Biased-accuracy 10\%) } & $0.192 \mathrm{~g} / \mathrm{mm}^{3}$ & $0.0134 \mathrm{~g} / \mathrm{mm}^{3}$ & 11.50 & 5.00 & $43 \%$ \\
\hline \multicolumn{2}{|c|}{ Consultant 4 (Biased-accuracy 10\%) } & $0.168 \mathrm{~g} / \mathrm{mm}^{3}$ & $0.0134 \mathrm{~g} / \mathrm{mm}^{3}$ & 13.50 & 6.00 & $44 \%$ \\
\hline \multirow{2}{*}{$\begin{array}{c}\text { Consultant } 5 \\
\text { (Unbiased-accuracy 25\%) }\end{array}$} & $\mathrm{C}_{0}:$ & $0.156 \mathrm{~g} / \mathrm{mm}^{3}$ & $0.0147 \mathrm{~g} / \mathrm{mm}^{3}$ & \multirow{2}{*}{14.00} & \multirow{2}{*}{4.50} & \multirow{2}{*}{$32 \%$} \\
\hline & Cover: & $30 \mathrm{~mm}$ & $3.6 \mathrm{~mm}$ & & & \\
\hline
\end{tabular}

In the prior prediction of the TTT, $\sigma_{\text {TTT }}$ was 7.50 years and the $\mathrm{COV}_{\text {TTT }}$ was around $48 \%$; both values express the uncertainty in the first prediction. Based on the accuracy of the NDE consultants and the assumed inspection measurements $\mathrm{a}_{\mathrm{M}}$, it can be seen that updating the deterioration model using an NDE inspection can reduce the uncertainty in the model prediction. However, the reduction in some of the cases was smaller compared to other consultants and prior predictions. For example, due to the low accuracy of consultant 2 (i.e., $\pm 25 \%$ ), the reduction in the $\sigma_{\text {TTT }}$ was only 1 year and there was a $3 \%$ reduction in $\mathrm{COV}_{\text {TTT }}$ (compared to the prior), whereas when consultant 1 was considered (accuracy $\pm 10 \%$ ), the reduction in the $\sigma_{\text {TTT }}$ was 2.50 years and the $\operatorname{COV}_{\text {TTT }}$ decreased by $8 \%$.

The maximum reduction in uncertainty will be achieved by hiring consultant 5 , where the $\sigma_{\text {TTT }}$ and the $\mathrm{COV}_{\text {TTT }}$ compared with the prior will be reduced by 3 years and $16 \%$, respectively. Although the accuracy of the CIP method conducted by consultant 5 was lower than consultant 1 , which had the highest CIP accuracy, the reduction in the uncertainty was greater. This shows the importance of updating the concrete cover and how sensitive the model prediction is to the cover parameter, which agrees with the findings of [12]. It should be noted that if the accuracy of the CIP test of consultant 5 was similar to consultant 1 , the predicted TTT will have a $\mu_{\text {TTT }}$ and $\sigma_{\text {TTT }}$ of 12 and 3.50 years, with a $\operatorname{COV}_{\text {TTT }}$ of $29 \%$, which means even more improvement in the uncertainty reduction (i.e., $\mathrm{COV}_{\text {TTT }}$ reduced by $19 \%$ compared to the prior). Moreover, as shown in Table 9 , a low accuracy inspection (i.e., consultant 2) or a biased inspection such as with consultants 3 and 4 can misguide a bridge inspector and lead to inaccurate decisions regarding the TTT and appropriate time of repair. Thus, bridge inspection planners should give attention to the quality and 
accuracy of the NDE method. However, as the quality of the inspection increases, the cost of inspection will increase.

In some cases, enhancing the quality of the inspection by using a more accurate NDE or combining more than one NDE method can enhance the value of the inspection and reduce uncertainty regarding the TTT and repair time, which, as a result, can help in avoiding unnecessary repairs or expensive delayed repair activities, outweighing the increase in the inspection cost. Based on the information provided by [55], conducting an NDE inspection with a CIP test on a similar bridge to the E-17-HS will cost USD 8400. This inspection cost includes the cost of personnel, the maintenance of traffic, the snooper, laboratory analysis, and the CIP test. Hence, adding a cover meter (i.e., difference between consultant 1 and 5) to the inspection process can increase the cost of the inspection by a range of USD 500-USD $1500[48,56]$. In practice, a bridge inspection planner should consider both the reduction in uncertainty and the cost of inspection when choosing the inspection method, and this reduction in uncertainty regarding the TTT will either help in improving the maintenance decision process or it will not. Finally, based on the above analysis, it is assumed that consultant 5 will be hired by the agency to conduct the inspection at year 8 .

4.2.5. Task 5: Year 8, Incorporating Inspection Data in the Planning Process to Predict the Updated TTT and Choose the Following Inspection Time

To show how the collected inspection data impact the inspection planning process, four different inspection scenarios are assumed as the outcomes of the first NDE inspection conducted at year 8 . The analyses for each scenario are shown in Table 10, indicating how the inspection outcome can change the decision regarding the next inspection time and TTT. In scenario 1 , it was assumed that the average values of the measured $\mathrm{C}_{0}$ and cover are similar to the prior values illustrated in Table 3 (i.e., $C_{0}=0.15 \mathrm{~g} / \mathrm{mm}^{3}$ and cover $=30 \mathrm{~mm}$ ); however, the standard deviations were different due to the accuracy of the NDE test conducted by consultant 5 (see Table 7). In scenario 2, it was assumed that the surface chloride concentration will be higher (i.e., $\mathrm{C}_{0}=0.4 \mathrm{~g} / \mathrm{mm}^{3}$ ) than the prior and the concrete cover $($ Cover $=28 \mathrm{~mm}$ ) will be lower, leading to a faster rate of corrosion and a shorter TTT. On the other hand, in the third scenario, a slower corrosion rate was assumed with a lower surface chloride concentration $\left(\mathrm{C}_{0}=0.13 \mathrm{~g} / \mathrm{mm}^{3}\right)$ than the prior and a larger concrete cover $($ Cover $=32 \mathrm{~mm})$. In the last scenario, it was assumed that the concrete cover test failed, and no data were collected, but the measured surface chloride concentration was similar to the prior.

Bayesian updating was performed considering the new values measured during inspection as the likelihood (Table 10, column 2) and the parameter values stated in Table 3 as the prior. Then, the new posterior values shown in Table 10 (column 3 ) were obtained and used in the prediction model to find the new TTT and the corresponding inspection time using uncertainty propagation and lifetime functions (see Figure 6), similar to Section 4.2.2. According to scenario 1 , the TTT is expected to be at year 14.50, which is 1 year earlier than the prior prediction (i.e., prior TTT $=15.50$ years). When a faster corrosion rate was considered as in scenario 2, the TTT was expected to happen earlier at year 12.50, which is opposite to scenario 3, where the TTT was expected to be delayed by 2 years. Based on the inspection outcome, the TTT predicted and the associated uncertainty can change significantly, affecting the decision of the bridge inspector regarding the appropriate time and method of intervening or conducting a repair. For example, if maintenance is to be considered at TTT, based on the prior prediction, a preserving maintenance to reduce the corrosion rate could be conducted at year 15.50, but if the inspection outcome was similar to the one in scenario 2, this intervention should be done earlier at year 12.50 . 
Table 10. Statistical descriptors of the bridge condition and TTT based on the assumed inspection scenarios and posterior values.

\begin{tabular}{|c|c|c|c|c|c|}
\hline $\begin{array}{l}\text { Inspection } \\
\text { Scenario }\end{array}$ & $\begin{array}{c}\text { Value of Measured } \\
\text { Parameters (Likelihood) }\end{array}$ & $\begin{array}{c}\text { Posterior Value of } \\
\text { Measured Parameters }\end{array}$ & $\mathrm{C}_{\mathrm{ch}}\left(\mathrm{g} / \mathrm{mm}^{3}\right)$ & E[t] (Years) & $\sigma_{Y}$ (Years) \\
\hline \multirow{4}{*}{$\begin{array}{l}\text { Scenario (1): (Same } \\
C_{0} \text { and higher cover) }\end{array}$} & \multirow{4}{*}{$\begin{array}{c}\mathrm{C}_{0} \sim\left(0.15 \mathrm{~g} / \mathrm{mm}^{3}, 0.0375 \mathrm{~g} / \mathrm{mm}^{3}\right) \\
\quad \text { Cover }(30 \mathrm{~mm}, 4.5 \mathrm{~mm})\end{array}$} & \multirow{4}{*}{$\begin{array}{c}\mathrm{C}_{0} \sim\left(0.15 \mathrm{~g} / \mathrm{mm}^{3}, 0.014 \mathrm{~g} / \mathrm{mm}^{3}\right) \\
\quad \text { Cover } \sim(30 \mathrm{~mm}, 3.6 \mathrm{~mm})\end{array}$} & 0.025 & 9.50 & 3.00 \\
\hline & & & 0.030 & 11.00 & 3.50 \\
\hline & & & 0.035 & 12.50 & 4.00 \\
\hline & & & $0.040\left(\mathrm{C}_{\mathrm{th}}\right)$ & $14.50=\mu_{\mathrm{TTT}}$ & $5.00=\sigma_{\mathrm{TTT}}$ \\
\hline \multirow{4}{*}{$\begin{array}{c}\text { Scenario (2): (Higher } \\
\mathrm{C}_{0} \text { and } \\
\text { smaller cover) }\end{array}$} & \multirow{4}{*}{$\begin{array}{c}\mathrm{C}_{0} \sim\left(0.40 \mathrm{~g} / \mathrm{mm}^{3}, 0.1 \mathrm{~g} / \mathrm{mm}^{3}\right) \\
\text { Cover } \sim(28 \mathrm{~mm}, 4.2 \mathrm{~mm})\end{array}$} & \multirow{4}{*}{$\begin{array}{c}\mathrm{C}_{0} \sim\left(0.160 \mathrm{~g} / \mathrm{mm}^{3}, 0.0148 \mathrm{~g} / \mathrm{mm}^{3}\right) \\
\text { Cover } \sim(28.7 \mathrm{~mm}, 3.45 \mathrm{~mm})\end{array}$} & 0.025 & 8.50 & 2.50 \\
\hline & & & 0.030 & 9.50 & 3.50 \\
\hline & & & 0.035 & 11.00 & 4.00 \\
\hline & & & $0.040\left(\mathrm{C}_{\text {th }}\right)$ & $12.50=\mu_{\mathrm{TTT}}$ & $4.50=\sigma_{\mathrm{TTT}}$ \\
\hline \multirow{4}{*}{$\begin{array}{l}\text { Scenario (3): } \\
\text { (Smaller } \mathrm{C}_{0} \text { and } \\
\text { higher cover) }\end{array}$} & \multirow{4}{*}{$\begin{array}{c}\mathrm{C}_{0} \sim\left(0.13 \mathrm{~g} / \mathrm{mm}^{3}, 0.013 \mathrm{~g} / \mathrm{mm}^{3}\right) \\
\quad \text { Cover } \sim(32 \mathrm{~mm}, 4.8 \mathrm{~mm})\end{array}$} & \multirow{4}{*}{$\begin{array}{c}\mathrm{C}_{0} \sim\left(0.1385 \mathrm{~g} / \mathrm{mm}^{3}, 0.010 \mathrm{~g} / \mathrm{mm}^{3}\right) \\
\quad \text { Cover } \sim(31.22 \mathrm{~mm}, 3.74 \mathrm{~mm})\end{array}$} & 0.025 & 11.00 & 3.50 \\
\hline & & & 0.030 & 14.00 & 4.00 \\
\hline & & & 0.035 & 15.50 & 4.50 \\
\hline & & & $0.040\left(\mathrm{C}_{\mathrm{th}}\right)$ & $17.50=\mu_{\mathrm{TTT}}$ & $6.00=\sigma_{\mathrm{TTT}}$ \\
\hline \multirow{4}{*}{$\begin{array}{l}\text { Scenario (4): } \\
\left(\text { Smaller } \mathrm{C}_{0}\right)\end{array}$} & \multirow{4}{*}{$\mathrm{C}_{0} \sim\left(0.15 \mathrm{~g} / \mathrm{mm}^{3}, 0.0375 \mathrm{~g} / \mathrm{mm}^{3}\right)$} & \multirow{4}{*}{$\mathrm{C}_{0} \sim\left(0.15 \mathrm{~g} / \mathrm{mm}^{3}, 0.014 \mathrm{~g} / \mathrm{mm}^{3}\right)$} & 0.025 & 9.50 & 4.00 \\
\hline & & & 0.030 & 11.50 & 5.50 \\
\hline & & & 0.035 & 13.50 & 6.00 \\
\hline & & & $0.040\left(\mathrm{C}_{\mathrm{th}}\right)$ & $15.00=\mu_{\mathrm{TTT}}$ & $7.00=\sigma_{\text {TTT }}$ \\
\hline
\end{tabular}

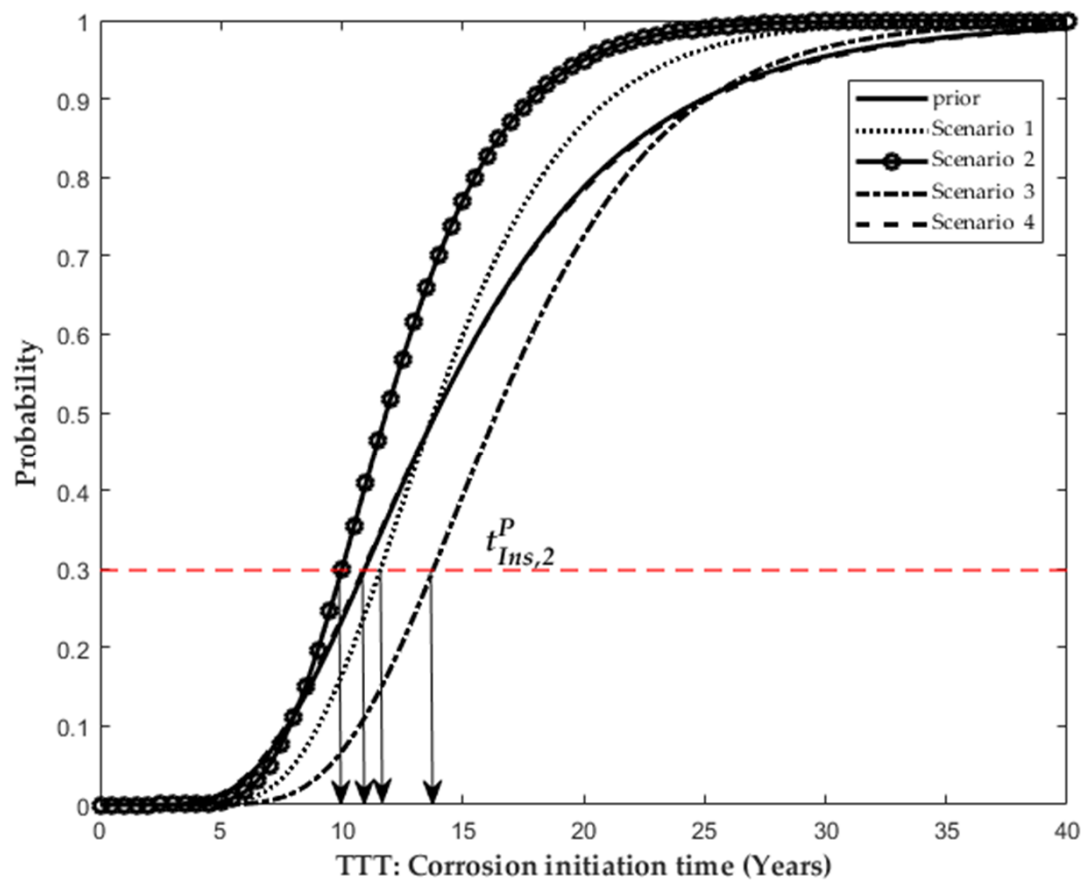

Figure 6. Cumulative probability of failure lifetime function $\mathrm{F}(\mathrm{t})$ based on inspection scenario.

Before choosing the next inspection time, $\mathrm{t}_{\mathrm{Ins}, 2}$, a bridge inspection planner should perform the expert-based assessment procedure and decide on the uncertainty thresholds, since the condition and risks surrounding the bridge could have changed. However, if the same uncertainty thresholds were used in this stage (i.e., $\sigma_{\text {th }}=3.75 y$ years and $P_{\text {th }}=30 \%$ ), according to scenario 1 , the second NDE inspection $t_{I n s, 2}$ is to be considered at year 12.50 or 12.00, where $\sigma_{Y}$ and $F(t)$ exceed 3.75 years and $30 \%$, respectively (see Table 10 and Figure 6). Hence, based on the minimum criteria adapted (i.e., the inspection $t_{I n s, 2}$ is the minimum of 
both $t_{I n s, 2}^{\sigma}$ and $t_{I n s, 2}^{P}$ ), the second inspection should be at $t_{I n s, 2}=12.00 y e a r r s$. With a similar approach considering scenarios 2 and 3, the next inspection $t_{I n s, 2}$ should be conducted at years $10.00\left(\mathrm{t}_{\mathrm{Ins}, 2}^{\mathrm{P}}=10\right.$ years) and $14.00\left(\mathrm{t}_{\mathrm{Ins}, 2}^{\sigma}=14\right.$ years $)$, respectively. This shows the value of the inspection outcome and how it can impact the next inspection time. Bridges where deterioration is happening as predicted, or more slowly, will be able to have longer stretches between inspections, while bridges that are showing faster deterioration will be inspected more frequently.

As mentioned earlier, in some cases, improving the inspection quality or combining more the one NDE method can help in reducing the uncertainty level regarding the TTT and corresponding repair time. In this context, the reason for assuming that scenario 4 happened during inspection is to show that improving the inspection quality, for example, by combining two NDE methods, can also help in reducing the number of inspections and total inspection cost during the life cycle of the bridge. When the cover meter was used as in scenario 1, this reduced the uncertainty, leading to a second inspection at year 12.00, which is almost 4.00 years from the last inspection at year 8 and about 2.5 years from the TTT when a maintenance can be considered. Meanwhile, in scenario 4, failing to measure the cover led to a very small reduction in uncertainty, which, according to the uncertainty thresholds, will require the bridge inspector to conduct an inspection at year 9.50, which is only 1.50 years from the last inspection. Although the inspection conducted with the cover meter will be more expensive, having a small gap between inspections and a small reduction in uncertainty can lead to more inspections, increasing the total inspection cost.

\subsection{Part 2: Applying the Proposed Framework on an Existing Bridge}

This part of the example moves forward in time and demonstrates how the uncertaintybased inspection framework can be applied on a bridge that has been operating for many years, where corrosion is already active, and the bridge is in the corrosion propagation stage. This part of the example also shows how the framework allows for consideration of more than one deterioration process at the same time. It is assumed that the bridge has been operating for 16 years, and the last visual inspection conducted at year 16 spotted hair cracks and rust stains on the concrete surface, indicating that corrosion is already active in the concrete substrate of the E-17-HS bridge and the bridge has entered the corrosion propagation stage. Thus, the proposed framework will be applied to choose the appropriate inspection time and methods after year 16 .

To show how this framework can plan for inspections while considering more than one deterioration process at the same time, in this part of the example and stage of the bridge service life, two primary deterioration mechanisms or limit states will be considered simultaneously, pitting corrosion of the steel reinforcement and cracking of the concrete cover due to corrosion. The average diameter of the transverse reinforcement in the E17-HS bridge deck is $16 \mathrm{~mm}$ [52], and accordingly, the allowable pitting corrosion depth (PCD) (i.e., limit state 1) is $4 \mathrm{~mm}$ [13]. Previous work also showed that concrete cracks tend to connect, causing longitudinal cracking and spalling at crack widths between 0.3 and $0.5 \mathrm{~mm}$ [57], whereas concrete cracks larger than $0.8 \mathrm{~mm}$ can have a significant impact on the serviceability of a bridge deck [58]. As such, a crack width limit of $0.6 \mathrm{~mm}$ will be assumed to represent severe cracking (i.e., limit state 2). After reaching either of the limit states, a repair activity should be considered by the agency.

Based on the above discussion, in this part of the example, the TTT will be the expected time to reach a pitting corrosion depth of $4 \mathrm{~mm}$ (TTT $\left.\mathrm{TCD}_{\mathrm{PC}}\right)$ or the time to reach a crack width of $0.6 \mathrm{~mm}$ (TTT $\mathrm{Tr}_{\mathrm{r}}$ ). The mechanistic models in Equation (A2) and Equation (A3) will be used to predict the $\mathrm{TTT}_{\mathrm{PCD}}$ and $\mathrm{TTT}_{\mathrm{C}}$, respectively. The random variables that will be used in both equations are defined in Table 11. 
Table 11. Values and probabilistic descriptors of parameters used in Equations (A2) and (A3).

\begin{tabular}{|c|c|c|c|c|c|}
\hline Variable & Notation (Units) & Mean & $\mathrm{COV}$ & Distribution & References \\
\hline Concrete cover & $\mathrm{X}(\mathrm{mm})$ & 30 & 0.2 & Lognormal & [52] \\
\hline Rate of corrosion & $\mathrm{r}_{\text {corr }}(\mathrm{mm} /$ year $)$ & 0.065 & 0.3 & Lognormal & [21] \\
\hline Corrosion current density & $\mathrm{i}_{\text {corr }}\left(\mu \mathrm{A} / \mathrm{cm}^{2}\right)$ & 1.2 & 0.3 & Lognormal & {$[59,60]$} \\
\hline Limiting crack width & $\mathrm{w}_{\lim }$ & $0.6 \mathrm{~mm}$ & - & - & [58] \\
\hline Water cement ratio & wc & 0.5 & 0.1 & Normal & {$[61]$} \\
\hline $\begin{array}{l}\text { Ratio between the maximum pit depth to } \\
\text { the mean pit depth }\end{array}$ & $\mathrm{V}$ & 5 & 0.1 & Normal & [62] \\
\hline Corrosion initiation time & $\mathrm{T}_{\mathrm{CI}}$ (years) & 14 & 0.15 & Lognormal & Assumed \\
\hline Time to reach a hair crack of size $0.05 \mathrm{~mm}$ & $\mathrm{t}_{1 \mathrm{st}}$ (years) & $\mathrm{T}_{\mathrm{CI}}+2 \mathrm{yrs}$ & - & - & {$[63,64]$} \\
\hline
\end{tabular}

4.3.1. Year 16, Choosing Next Inspection Time Considering Pitting Corrosion and Surface Cracking

Monte Carlo simulation and Equations (A2) and (A3) were used to predict both expected times to transition, $\mu_{\mathrm{TTT}} \mathrm{PCD}$ and $\mu_{\mathrm{TTT}_{\mathrm{Cr}}}$, and the corresponding $\sigma_{\mathrm{TTT}_{\mathrm{PCD}}}$ and $\sigma_{\mathrm{TTT}_{\mathrm{Cr}}{ }^{\prime}}$ respectively. Then, to choose the next inspection time based on the first uncertainty criterion (i.e., $\left.\sigma_{\mathrm{Y}} \geq \sigma_{\mathrm{th}}\right)$, the expected time to reach a certain pitting depth $\left(\mathrm{E}[\mathrm{t}]_{\mathrm{PCD}}\right)$ before reaching the maximum pitting corrosion depth $\left(\mathrm{TTT}_{\mathrm{PCD}}\right)$ and corresponding standard deviation $\left(\sigma_{Y, P C D}\right)$ were predicated, as shown in Table 12. Further, the expected time to reach certain crack sizes $\left(\mathrm{E}[\mathrm{t}]_{\mathrm{Cr}}\right)$ before reaching the maximum allowable crack size and corresponding standard deviation $\left(\sigma_{Y, C r}\right)$ were obtained, as shown in Table 13.

Table 12. The expected time $\mathrm{E}[\mathrm{t}]_{\mathrm{PCD}}$ to reach a certain pitting corrosion depth (PCD) and the corresponding $\sigma_{Y, P C D}$.

\begin{tabular}{ccc}
\hline PCD $(\mathbf{m m})$ & $\left.\mathbf{E}_{\mathbf{t}}\right]_{\mathbf{P C D}}$ (Years) & $\boldsymbol{\sigma}_{\mathbf{Y}, \mathbf{P C D}}$ (Years) \\
\hline 1.00 & 18.50 & 2.00 \\
\hline 1.50 & 20.00 & 2.50 \\
\hline 2.00 & 21.50 & 3.00 \\
\hline 2.50 & 23.00 & 3.50 \\
\hline 3.00 & 25.50 & 4.00 \\
\hline 3.50 & 26.50 & 5.00 \\
\hline $4.00($ Limit state 1$)$ & $28.50\left(\mathrm{TTT}_{\mathrm{PCD}}\right)$ & $6.50\left(\sigma_{\mathrm{TTT}}\right)$ \\
\hline
\end{tabular}

Table 13. The expected time $\mathrm{E}[\mathrm{t}]_{\mathrm{Cr}}$ to reach a certain crack length and the corresponding $\sigma_{\mathrm{Y}, \mathrm{Cr}}$.

\begin{tabular}{ccc}
\hline Crack Width $(\mathbf{m m})$ & $\left.\boldsymbol{E}_{\mathbf{t}}\right]_{\mathrm{Cr}}($ Years $)$ & $\boldsymbol{\sigma}_{\mathbf{Y}, \mathrm{Cr}}($ Years $)$ \\
\hline $0.30^{* *}$ & 22.00 & 2.50 \\
\hline 0.35 & 23.50 & 3.00 \\
\hline 0.40 & 24.00 & 3.50 \\
\hline 0.45 & 25.00 & 4.00 \\
\hline 0.50 & 25.50 & 4.50 \\
\hline 0.55 & 27.00 & 5.50 \\
\hline 0.60 (Limit state 2) & $28.00\left(\mathrm{TTT}_{\mathrm{Cr}}\right)$ & $6.00\left(\sigma_{\mathrm{TTT}_{\mathrm{Cr}}}\right)$ \\
\hline
\end{tabular}

** The propagation started with $0.3 \mathrm{~mm}$ because this is the minimum limit of the model [61]. 
Further, the cumulative probability of transition lifetime function for both limit states have been obtained and are illustrated in Figure 7, in order to help in choosing the next inspection time based on the second criterion (i.e., $F(t) \geq P_{t h}$ ). As shown in Table 12, the expected $\mathrm{TTT}_{\mathrm{PCD}}$ (i.e., time to reach a $4 \mathrm{~mm}$ depth of pitting corrosion in the steel rebar diameter) will be at $\mu_{\mathrm{TTT}}{ }_{\mathrm{PCD}}=28.50$ years, with a $\sigma_{\mathrm{TTT}_{\mathrm{PCD}}}=6.50$ years. Meanwhile, as shown in Table 13, the expected TTT $_{\mathrm{Cr}}$ (i.e., time for surface cracks to reach a maximum width of $0.6 \mathrm{~mm}$ ) will be at $\mu_{\mathrm{TTT}_{\mathrm{Cr}}}=28.00$ years, with a $\sigma_{\mathrm{TTT}_{\mathrm{Cr}}}=6.00$ years. Further, a bridge inspection should be considered once $\sigma_{Y, P C D}$ or $\sigma_{Y, C r}$ exceed the uncertainty threshold $\sigma_{\text {th }}$, or when the cumulative probability of transition $\mathrm{F}(\mathrm{t})$ for pitting corrosion or crack length exceeds the second criterion threshold $\mathrm{P}_{\mathrm{th}}-$ whichever happens first.

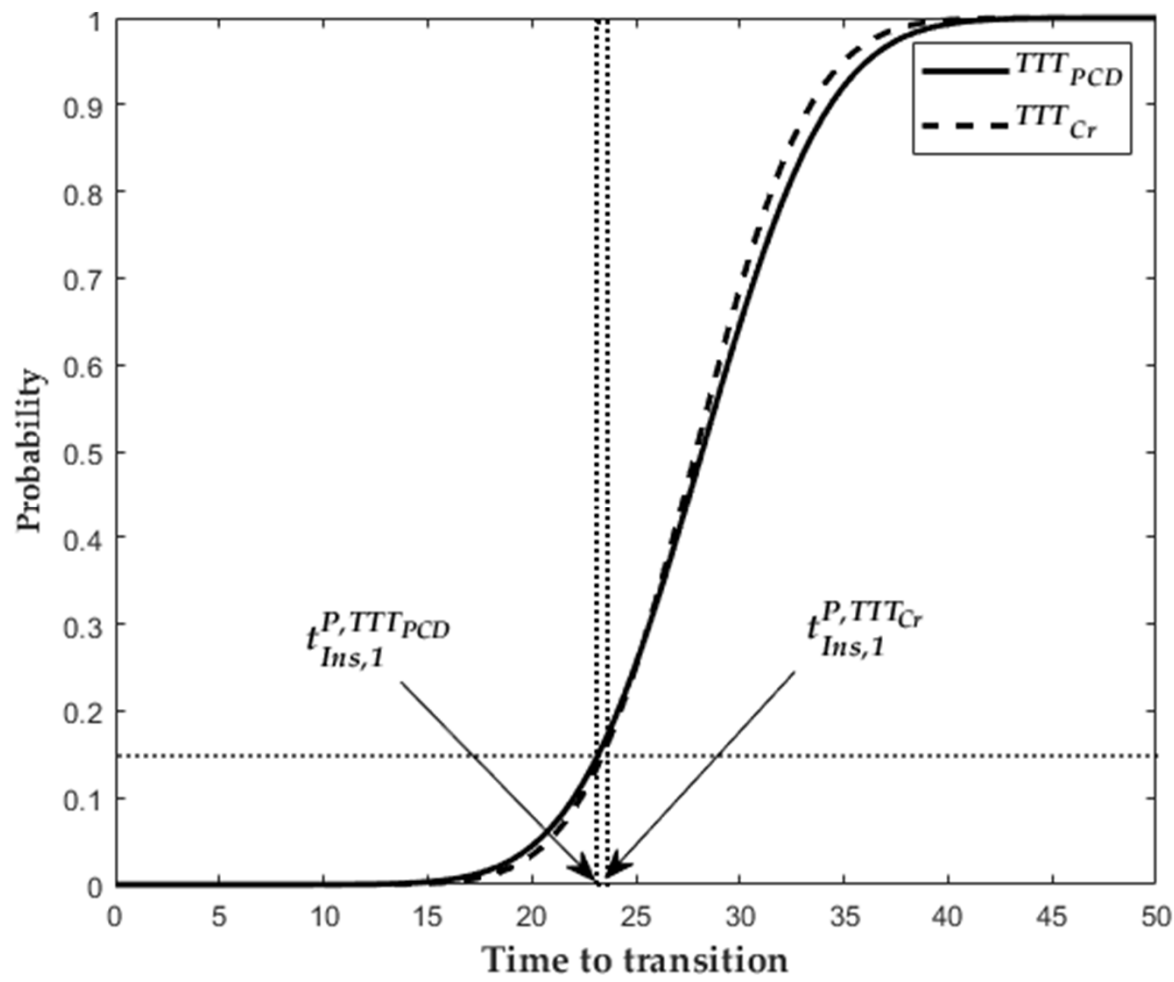

Figure 7. Cumulative probability of transition $\mathrm{F}(\mathrm{t})$ for time to transition $\left(\mathrm{TTT}_{\mathrm{PCD}}\right.$ and $\left.\mathrm{TTT}_{\mathrm{Cr}}\right)$.

\subsubsection{Year 16, Determining the Uncertainty Thresholds $\sigma_{\text {th }}$ and $P_{\text {th }}$}

The expert-based assessment process to choose the uncertainty thresholds should be conducted as demonstrated in Section 3.2.3. It should be noted that in this example, the decision process for choosing the thresholds for both deterioration mechanisms (pitting corrosion and surface cracking) can be the same since the damage modes considered are both due to corrosion. Alternatively, if a different deterioration mechanism (other than corrosion) or bridge component (other than the bridge deck) was considered such as fatigue cracking for steel elements, then another decision process has to be conducted with factors and considerations relevant to fatigue as a deterioration process.

The bridge in this part of the example has been operating for 16 years now and corrosion is already active with signs of hair cracks and stains. Accordingly, it was assumed that the bridge NBI rating dropped to 6 with an initial maximum score equal to 80 (see Table 1). Table 14 shows the points that will be deducted from the initial score based on the new conditions of the bridge after 16 years and assuming that ADTT has increased over the years and cracks and pitting corrosion will affect the deck capacity. 
Table 14. Points that will be deducted based on the P\&C factors.

\begin{tabular}{|c|c|c|}
\hline Performance Factors & E-17-HS Condition & Points Deducted \\
\hline $\begin{array}{l}\text { Deck drainage system } \\
\text { and ponding }\end{array}$ & The deck does not have a drainage system & -10 \\
\hline $\begin{array}{l}\text { Year of onstruction or } \\
\text { replacement maintenance }\end{array}$ & Bridge has been operating for more than 15 years now & -5 \\
\hline $\begin{array}{l}\text { Protective layer over } \\
\text { concrete surface }\end{array}$ & The deck has an asphalt overlay but with limited effectiveness & -5 \\
\hline Bridge skewness & The bridge is not skew & 0 \\
\hline $\begin{array}{l}\text { Average daily truck } \\
\text { traffic (ADTT) }\end{array}$ & The ADTT has increased to a moderate level & -5 \\
\hline Subjectivity to overspray & $\begin{array}{l}\text { The bridge crosses over a roadway exposed to deicing salts and has a clearance } \\
\text { of } 5 \mathrm{~m} \text { which makes it subject to moderate overspray }\end{array}$ & -5 \\
\hline Reinforcement type & Uncoated carbon steel bars & -10 \\
\hline Consequence Factors & E-17-HS Condition & Points Deducted \\
\hline $\begin{array}{l}\text { Damage to the top of } \\
\text { the bridge }\end{array}$ & $\begin{array}{l}\text { Bridge E-17-HS has a moderate average daily traffic ranging from } \\
600 \text { to } 1000 \text { vehicles per day and any damage to the top of the bridge or closing } \\
\text { the bridge for long durations of maintenance can cause moderate delays }\end{array}$ & -5 \\
\hline Features under the bridge & $\begin{array}{l}\text { The bridge crosses over a highway (Interstate-25) and any spalling of concrete } \\
\text { due to corrosion could cause major traffic delays and may cause } \\
\text { accidents or injuries }\end{array}$ & -10 \\
\hline Structural capacity & $\begin{array}{l}\text { Pitting corrosion and cracking will affect the capacity of the steel reinforcement } \\
\text { and the concrete deck }\end{array}$ & -5 \\
\hline Alternative routes & $\begin{array}{l}\text { There are two main alternative routes that the public can use if the bridge was } \\
\text { closed, to avoid public delays as much as possible }\end{array}$ & 0 \\
\hline
\end{tabular}

According to Table 14, 60 points will be deducted from the initial score, leading to a final score equal to 20, putting the bridge in the low category (see Figure 2). Table 6 will be used to calculate the new threshold values that can be implemented in the scale shown in Figure 2. Accordingly, $\mathrm{P}_{\text {th }}$ will equal $15 \%$ and since $\sigma_{\mathrm{TTT}}=6$ years, which is smaller than $\sigma_{\mathrm{TTT}}{ }_{\mathrm{PCD}}=6.5$ years, then $\sigma_{\text {th }}$ will equal $0.3 \sigma_{\mathrm{TTT}_{\mathrm{Cr}}}$, which is almost 2 years. Based on Tables 12 and 13 and the uncertainty threshold for the first criterion $\left(\sigma_{\mathrm{th}}=2\right.$ years), inspection should be considered at years 18.5 and $22\left(t_{\text {Ins,1 }}^{\sigma, \mathrm{TTT}_{\mathrm{PCD}}}=18.5 \mathrm{yrs}, \mathrm{t}_{\mathrm{Ins}, 1}^{\sigma, \mathrm{TTT}}=22 \mathrm{yrs}\right)$. Meanwhile, based on the second criterion and Figure 7, inspection should be considered around the years 24 and $24.5\left(t_{\text {Ins, }, 1}^{\mathrm{P}, \mathrm{TTP}_{\mathrm{PCD}}}=24 \mathrm{yrs}, \mathrm{t}_{\text {Ins, } 1}^{\mathrm{P}, \mathrm{TT}_{\mathrm{Cr}}}=24.5 \mathrm{yrs}\right)$. According to the minimum criteria used in the framework, an inspection should be performed at year 18.5, which is the smallest of all four inspection times and is 2.5 years from the last visual inspection at year 16 .

At this stage of the bridge service life, to update both deterioration models (Equations (A2) and (A3)), along with the concrete cover, the corrosion current density $\mathrm{i}_{\text {corr }}$ or the rate of corrosion $\mathrm{r}_{\text {corr }}\left(\mathrm{r}_{\text {corr }}=\mathrm{i}_{\text {corr }} \times \mathrm{V} \times 0.0115\right.$ [59]) can be evaluated onsite using a linear polarization test (LPR) [65] at the time of inspection. If various consultants offered their services, the bridge inspection planner can choose between them after conducting the pre-posterior analysis considering the accuracy of each consultant. In Part 2 of the example, it is assumed that until now, only visual inspections have been conducted in the service life of the bridge and no records are available regarding the corrosion rate. Thus, for conducting the pre-posterior analysis and to choose the appropriate NDE method or consultant, the inspection outcome (value of the corrosion rate at year 18.5) needs to be estimated. However, unlike the surface chloride concentration in Part 1 , the $i_{\text {corr }}$ and $r_{\text {corr }}$ at year 18.5 can be estimated using the prediction model stated by [19], which predicts how the corrosion rate will change with time. 
Finally, after choosing the inspection time (year 18.5) and the inspection method, the final step is to conduct the inspection and use the inspection results to update the deterioration models using the Bayesian theorem.

\section{Discussion}

As shown in Part 1 of the example (the case of a new bridge), the proposed framework allowed for conducting only three inspections in an almost 12-year period following construction (i.e., one visual inspection and two NDE inspections). Meanwhile, if the currently used standard bridge inspection program [2] was adopted, six visual routine inspections would have been required in those 12 years based on a two-year fixed inspection interval. Furthermore, it is likely that some of these routine inspections would have been followed by in-depth inspections due to the limitations of visual evaluation. Nasrollahi and Washer [41] found that for bridge superstructures in good condition, the two-year inspection cycle can be short and result in unnecessary inspections, and that scheduling inspections based on the bridge condition can result in reducing the number of inspections as was demonstrated herein. Further, using only expert opinion, Washer, et al. [66] verified that inspection intervals for bridges with an NBI rating of 7 or higher can be 4 to 6 years. Similarly, after applying the proposed framework and using both expert opinion and quantitative methods in Part 1 of the example, it was found that for a bridge deck in a new condition, the inspection can be conducted at year 8 , which would be 6 years after the first routine visual inspection conducted at year 2 . In addition to what was presented by [66] and [41], we provided an approach to choose the suitable inspection technique that can effectively evaluate the bridge condition.

Maintenance decisions depend mainly on inspection results and quality. In the application of the proposed framework, it was found that conducting a high-quality nondestructive inspection after only 8 years from the bridge construction can reduce the uncertainty regarding the timing of the bridge repair by $16 \%$ as well as reducing the number of future inspections. Soliman, et al. [67] also concluded that a limited number of high-quality inspections can prevent damage detection delay and reduce the number of inspections. Kim and Frangopol [17] found that replacing visual inspections with high-quality NDE early in the bridge deck service life can be cost-effective and help avoid redundant or delayed maintenance actions and bridge failure. However, the quality of the inspection in $[17,67]$ was defined using the probability of detection which, for some NDE techniques, can be difficult or expensive to obtain. Thus, in our method, we defined the quality of inspection by its accuracy and ability to reduce uncertainty regarding the bridge condition.

Kim, Ge and Frangopol [25] recommended the use of Bayesian updating to incorporate inspection findings in the inspection planning process and update prediction model parameters. They found that inspection data can lead to better scheduling of future inspections and repairs which can help in allocating resources efficiently and prioritizing bridges that are in more need of maintenance actions than others. After analyzing different inspection scenarios herein, we found that inspection results can have a significant effect on the bridge management process and can lead to rescheduling interventions. We also found that incorporating inspection results can help in reducing the number of inspections as a result of reducing uncertainty regarding the timing of the bridge repair and the need to conduct more inspections.

Considering more than one bridge component or deterioration during the planning process was one of the main purposes of this study. Soliman, Frangopol and Kim [23] considered more than one fatigue-sensitive detail in their inspection planning process. However, a single deterioration model able to predict the fatigue crack propagation was used for all details. Hence, using a new approach in Part 2 of our example (existing bridge case), we included two different deterioration models simultaneously in the inspection planning process. This explains how the proposed framework can help bridge owners consider more than one deterioration process or bridge component during the inspection planning process. 
Liu and Frangopol [35] commented on how the attitude of bridge owners towards risk and bridge maintenance can have an effect on the inspection time and method and can impact the value of inspection information. In our study, expert judgement was used to choose the uncertainty thresholds. Based on the bridge owners' attitude towards risk and the consequence of a bridge failure, inspection schedules were established. Liu and Frangopol [35] found that bridge managers with a risk-averse attitude preferred conducting inspections earlier in the bridge service life. On this basis, due to the flexibility of the proposed framework, bridge owners with a more risk-averse attitude can choose smaller uncertainty thresholds, leading to more frequent and earlier inspections even if the bridge was new and deterioration was predicted to be in the early stages.

Further, Kim, Frangopol and Soliman [13] indicated that including the consequence of a failure in the inspection planning process can affect the inspection schedule and representing the failure outcome using a high failure cost can lead to more inspections. However, their concern was that putting a monetary value on bridge failure can lead to inaccuracies in the decision process. Thus, in the presented uncertainty-based inspection framework, the consequence of a failure is considered using expert judgement. We found that considering the consequence of a failure when choosing the uncertainty thresholds can reduce inspection intervals for a new bridge due to the risks associated with the bridge failure or delayed maintenance. This can increase number of inspections but will help in maintaining a safe and reliable transportation system.

Overall, the framework presented in this paper builds on the work other researchers have provided in the field of bridge inspection planning. The framework presents a new and practical approach for inspection planning that simply ties different approaches together into one comprehensive framework able to enhance the bridge management process.

\section{Conclusions and Future Research}

A new approach for bridge inspection planning was presented in this paper to help bridge owners determine the bridge inspection time and method by incorporating information from deterioration models, NDE inspection data, and expert judgement. The uncertainty-based inspection framework was developed with the objective to enhance the inspection efficiency, reduce uncertainty regarding the bridge maintenance time, and help bridge inspectors choose the inspection method that is appropriate for the stage of the bridge's life. In the proposed framework, inspections are considered as means to reduce the uncertainty regarding the bridge condition and update prediction models that can predict future bridge performance. Two criteria are used to schedule inspections, the standard deviation associated with bridge condition before reaching the time to transition (TTT) and the probability to reach the TTT. The approach was applied on an RC bridge in Colorado exposed to corrosion deterioration. Based on the analysis conducted in this study, the following conclusions can be drawn:

1. One of the main contributions of this study is to help bridge owners avoid delayed or unnecessary inspections. In the example, during a 12-year period, the proposed framework helped in reducing the number of inspections by $50 \%$ compared to the traditional uniform calendar-based approach while combining both routine visual inspections and in-depth inspections into a single inspection. Using the proposed uncertainty quantification methods to schedule inspections and conducting inspections only to reduce uncertainty regarding the bridge condition can help in utilizing inspection resources more efficiently.

2. The framework provides a clear guide on how to select the appropriate inspection procedure using Bayesian and regression analysis while considering the bridge deterioration stage, model parameters that need to be updated, and inspection accuracy. As shown in the example, inspection methods are selected based on their ability to reduce the uncertainty regarding the transition in the bridge deck condition and repair time. This can help in improving the value of the data gathered during inspections and hence improve maintenance decisions. 
3. The analysis conducted in this study showed that improving the inspection accuracy can not only help in reducing the uncertainty regarding the bridge condition but can also help in reducing the number of inspections. Different inspection scenarios were compared, and it was found that when the concrete cover was not updated and the chloride content was measured by a relatively low accuracy, more inspections were required in the near future to reduce the uncertainty level.

4. Most of the presented inspection planning frameworks in the literature are limited to new bridges or a single deterioration mechanism. In Part 2 of the example, the framework was demonstrated on an existing bridge, and pitting corrosion of the steel reinforcement and concrete cover cracks were both considered simultaneously during the inspection planning process. This shows how the framework can be tailored to different types of bridge deteriorations and components, which is a major advancement compared to other inspection planning frameworks where only a single deterioration mechanism is considered

5. The process used to choose the uncertainty thresholds considers the consequence of the bridge failure and additional factors impacting the bridge performance other than the ones considered in the deterioration models. Due to this contribution, the risks associated with a bridge condition are considered during inspection planning to enhance the safety and serviceability of the bridge.

Finally, the use and potential benefits of the proposed framework still require further analysis and research. The application of the framework needs to be extended and realtime investigations on complex bridges should be conducted. Since the framework is still under development and has not been applied in practice, it is recommended not to use the framework on a new bridge before conducting an initial or routine inspection or on a structurally deficient bridge. Having a variable inspection interval can make it difficult for bridge owners to plan their budget for inspecting the bridges in their inventory. Therefore, this methodology should be developed to help bridge owners in estimating the bridge inspection life cycle cost. Some tasks in the framework require a background in statistics and software coding, which might not be available in some personnel working in government agencies. Thus, before implementing this program, some employees will require specific preparation. Further, including the effects of bridge redundancy and load ratings in the framework can help in improving the planning process even more.

Author Contributions: The authors confirm contributions to the paper as follows: conceptualization, A.M.A., R.A.A., M.E.O.; formal analysis, A.M.A.; funding acquisition, R.A.A., M.E.O.; investigation, A.M.A., R.A.A., M.E.O.; methodology, A.M.A., R.A.A., M.E.O.; project administration, R.A.A., M.E.O.; supervision, R.A.A., M.E.O.; validation, A.A, R.A.A.; visualization, A.M.A.; writing-original draft, A.M.A., R.A.A., M.E.O.; writing-review and editing, A.M.A., R.A.A., M.E.O. All authors have read and agreed to the published version of the manuscript.

Funding: This research was funded by the U.S. Department of Transportation via a subcontract from North Dakota State University, grant number [FAR0023139], with matching support from Colorado State University.

Institutional Review Board Statement: Not applicable.

Informed Consent Statement: Not applicable.

Data Availability Statement: Not applicable.

Acknowledgments: The work presented in this paper was conducted with support from Colorado State University and the Mountain-Plains Consortium, a University Transportation Center funded by the U.S. Department of Transportation. The contents of this paper reflect the views of the authors, who are responsible for the facts and accuracy of the information presented.

Conflicts of Interest: The authors declare no conflict of interest. 


\section{Appendix A. Corrosion Mechanistic Deterioration Models}

The deterioration of reinforced concrete $(\mathrm{RC})$ structures occurs mainly due to corrosion of the reinforcement, which can be a result of carbonation or chloride ion penetration [54]. This paper is concerned with corrosion of RC structures due to chloride ion penetration, and this deterioration mechanism consists of two main stages: corrosion initiation and propagation $[68,69]$. Corrosion of steel reinforcement initiates once the chloride concentration at the rebar level reaches a certain threshold [70]. The time for corrosion initiation can be predicted using the following deterioration model, Equation(A1) [61,71]:

$$
\mathrm{T}_{\mathrm{CI}}=\frac{\mathrm{x}^{2}}{4 \mathrm{D}_{\mathrm{C}}}\left[\operatorname{erf}^{-1}\left(\frac{\mathrm{C}_{0}-\mathrm{C}_{\text {th }}}{\mathrm{C}_{0}}\right)\right]^{-2}
$$

where $\mathrm{T}_{\mathrm{CI}}$ is the corrosion initiation time associated with the critical chloride concentration $\mathrm{C}_{\mathrm{th}}, \mathrm{C}_{0}$ is the surface chloride content, $\mathrm{D}_{\mathrm{c}}$ is the diffusion coefficient, $\operatorname{erf}^{-1}($.$) is the inverse$ of the error function, and $\mathrm{x}$ is the depth from the concrete surface.

Corrosion propagation in an RC structure can cause loss of the reinforcement crosssectional area, a reduction in the bond strength, and cracks in the concrete cover. The loss of the reinforcement cross-sectional area can be due to uniform corrosion or pitting corrosion. Based on studies conducted by [72,73], pitting corrosion has a higher effect on the capacity of RC structures as it leads to a larger reduction in the area of the steel reinforcement. The pitting corrosion depth (PCD) in the steel reinforcement can be estimated as a timedependent deterioration using Equation (A2) [62]:

$$
\operatorname{PCD}(\mathrm{t})=\mathrm{r}_{\text {corr }} \mathrm{V}\left(\mathrm{t}-\mathrm{T}_{\mathrm{CI}}\right)
$$

where $\mathrm{r}_{\mathrm{corr}}$ is the rate of corrosion, and $\mathrm{V}$ is the ratio between the maximum pit depth to the mean pit depth (values of $V$ range 4 8) [73]. Another deterioration that can happen to concrete decks in the corrosion propagation stage is cracking of the concrete cover, in which hair cracks start appearing on the surface and then grow in length and width, causing excessive cracking to the concrete surface. In this paper, an empirical mechanistic model proposed by [61] will be used to estimate the time for cracks to grow from hair cracks (i.e., $0.05 \mathrm{~mm}$ ) to a severe crack limit (the severe crack limit will be discussed later in the paper), as shown in Equation (A3).

$$
\mathrm{T}_{\mathrm{SEV}}=\mathrm{t}_{1 \mathrm{st}}+0.0167 \mathrm{i}_{\text {corr }}^{-1.1}\left[42.9(\mathrm{wc} / \mathrm{C})^{-0.54}+\left(\frac{\mathrm{w}_{\text {lim }}-0.3}{0.0062}\right)^{1.5}\right]
$$

where $\mathrm{T}_{\mathrm{SEV}}$ is the time to reach a severe or excessive crack width, $\mathrm{t}_{\mathrm{st}}$ is the time to reach a hair crack of size $0.05 \mathrm{~mm}, \mathrm{i}_{\mathrm{corr}}=$ corrosion current density, $\mathrm{wc}=$ water $/$ cement ratio, $\mathrm{C}=$ concrete cover, and $\mathrm{w}_{\mathrm{lim}}=$ the severe limiting crack width. Note that the model only works for crack limits in a specific range: $\left(0.3 \mathrm{~mm} \leq \mathrm{w}_{\text {lim }} \leq 1.0 \mathrm{~mm}\right)$.

\section{References}

1. Dorafshan, S.; Maguire, M. Bridge inspection: Human performance, unmanned aerial systems and automation. J. Civ. Struct. Heal. Monit. 2018, 8, 443-476. [CrossRef]

2. FHWA. National Bridge Inspection Standards (NBIS); Federal Highway Adminstration: Washington, DC, USA, 2012.

3. Washer, G.; Connor, R.; Nasrollahi, M.; Provines, J. New Framework for Risk-Based Inspection of Highway Bridges. J. Bridg. Eng. 2016, 21, 04015077. [CrossRef]

4. ASCE/SEI-AASHTO-Ad-hoc, G.O.B.I.; Rating; Rehabilitation. White paper on bridge Inspection, rating, rehabilitation, replacement. Am. Soc. Civ. Eng. 2009, 14. [CrossRef]

5. Washer, G.; Nasrollahi, M.; Applebury, C.; Connor, R.; Ciolko, A.; Kogler, R.; Fish, P.; Forsyth, D. Proposed Guideline for ReliabilityBased Bridge Inspection Practices; National Academy of Sciences (Project 12-82 (01)): Washigton, DC, USA, 2014.

6. Lin, Z.; Pan, H.; Wang, X.; Li, M. Improved Element-Level Bridge Inspection Criteria for Better Bridge Management and Preservation. Available online: https://www.ugpti.org/resources/reports/downloads/mpc19-403.pdf (accessed on 10 February 2021).

7. Phares, B.M.; Washer, G.A.; Rolander, D.D.; Graybeal, B.A.; Moore, M. Routine Highway Bridge Inspection Condition Documentation Accuracy and Reliability. J. Bridg. Eng. 2004, 9, 403-413. [CrossRef] 
8. Hearn, G. Bridge Inspection Practices (NCHRP-375); National Cooperative Highway Research Program: Washington, DC, USA, 2007; Volume 375.

9. Agrawal, A.; Alampalli, S. Inspection needs of deteriorating bridge components. Bridge Maint. Saf. Manag. Life Cycle Optim. 2010, 20100869, 147. [CrossRef]

10. Gucunski, N.; Imani, A.; Romero, F.; Nazarian, S.; Yuan, D.; Wiggenhauser, H.; Shokouhi, P.; Taffe, A.; Kutrubes, D. The Second Strategic Highway Research Program; Library of Congres: Washington, DC, USA, 2013.

11. Hesse, A.A.; Atadero, R.A.; Ozbek, M.E. Uncertainty in Common NDE Techniques for Use in Risk-Based Bridge Inspection Planning: Existing Data. J. Bridg. Eng. 2015, 20, 04015004. [CrossRef]

12. Morcous, G.; Lounis, Z.; Cho, Y. An integrated system for bridge management using probabilistic and mechanistic deterioration models: Application to bridge decks. KSCE J. Civ. Eng. 2010, 14, 527-537. [CrossRef]

13. Kim, S.; Frangopol, D.M.; Soliman, M. Generalized Probabilistic Framework for Optimum Inspection and Maintenance Planning. J. Struct. Eng. 2013, 139, 435-447. [CrossRef]

14. Biondini, F.; Frangopol, D.M. Life-Cycle Performance of Deteriorating Structural Systems under Uncertainty: Review. J. Struct. Eng. 2016, 142, 4016001. [CrossRef]

15. FHWA. Proposed Changes to the National Bridge Inspection Standards (NBIS). Available online: https://www.fhwa.dot.gov/ bridge/inspection/webinar.pdf (accessed on 17 November 2020).

16. Gucunski, N.; Pailes, B.; Kim, J.; Azari, H.; Dinh, K. Capture and Quantification of Deterioration Progression in Concrete Bridge Decks through Periodical NDE Surveys. J. Infrastruct. Syst. 2017, 23, 4016005. [CrossRef]

17. Kim, S.; Frangopol, D.M. Decision making for probabilistic fatigue inspection planning based on multi-objective optimization. Int. J. Fatigue 2018, 111, 356-368. [CrossRef]

18. Paris, P.; Erdogan, F. A Critical Analysis of Crack Propagation Laws. J. Basic Eng. 1963, 85, 528-533. [CrossRef]

19. Vu, K.A.T.; Stewart, M.G. Structural reliability of concrete bridges including improved chloride-induced corrosion models. Struct. Saf. 2000, 22, 313-333. [CrossRef]

20. Chung, H.-Y.; Manuel, L.; Frank, K.H. Optimal Inspection Scheduling of Steel Bridges Using Nondestructive Testing Techniques. J. Bridg. Eng. 2006, 11, 305-319. [CrossRef]

21. Kim, S.; Frangopol, D.M. Inspection and monitoring planning for RC structures based on minimization of expected damage detection delay. Probabilistic Eng. Mech. 2011, 26, 308-320. [CrossRef]

22. Kim, S.; Frangopol, D.M. Cost-Based Optimum Scheduling of Inspection and Monitoring for Fatigue-Sensitive Structures under Uncertainty. J. Struct. Eng. 2011, 137, 1319-1331. [CrossRef]

23. Soliman, M.S.; Frangopol, D.M.; Kim, S. Probabilistic optimum inspection planning of steel bridges with multiple fatigue sensitive details. Eng. Struct. 2013, 49, 996-1006. [CrossRef]

24. Soliman, M.; Frangopol, D.M. Erratum for "Life-Cycle Management of Fatigue-Sensitive Structures Integrating Inspection Information" by S. Mohamed Soliman and Dan M. Frangopol. J. Infrastruct. Syst. 2014, 20, 08014001. [CrossRef]

25. Kim, S.; Ge, B.; Frangopol, D.M. Effective optimum maintenance planning with updating based on inspection information for fatigue-sensitive structures. Probabilistic Eng. Mech. 2019, 58, 103003. [CrossRef]

26. Yang, D.Y.; Frangopol, D.M. Probabilistic optimization framework for inspection/repair planning of fatigue-critical details using dynamic Bayesian networks. Comput. Struct. 2018, 198, 40-50. [CrossRef]

27. Okasha, N.M.; Frangopol, D.M. Redundancy of structural systems with and without maintenance: An approach based on lifetime functions. Reliab. Eng. Syst. Saf. 2010, 95, 520-533. [CrossRef]

28. Kwon, K.; Frangopol, D.M. Bridge fatigue assessment and management using reliability-based crack growth and probability of detection models. Probabilistic Eng. Mech. 2011, 26, 471-480. [CrossRef]

29. Dong, Y.; Frangopol, D.M. Risk-informed life-cycle optimum inspection and maintenance of ship structures considering corrosion and fatigue. Ocean Eng. 2015, 101, 161-171. [CrossRef]

30. Straub, D.; Faber, M.H. On the Relation Between Inspection Quantity and Quality. In Proceedings of the 3rd European-American Workshop on NDE Re-liability, Berlin, Germany; pp. 1-14. Available online: http:/ / www.ndt.net/article/v09n07/straub/straub.pdf (accessed on 5 January 2021).

31. Orcesi, A.D.; Frangopol, D.M. Use of Lifetime Functions in the Optimization of Nondestructive Inspection Strategies for Bridges. J. Struct. Eng. 2011, 137, 531-539. [CrossRef]

32. Soliman, M.; Frangopol, D.M. Reliability and Remaining Life Assessment of Fatigue Critical Steel Structures: Integration of Inspection and Monitoring Information. Structures Congress 2013 2013, 709-720. [CrossRef]

33. Frangopol, D.M.; Dong, Y.; Sabatino, S. Bridge life-cycle performance and cost: Analysis, prediction, optimisation and decisionmaking. Struct. Infrastruct. Eng. 2017, 13, 1239-1257. [CrossRef]

34. Estes, A.C.; Frangopol, D.M. Updating Bridge Reliability Based on Bridge Management Systems Visual Inspection Results. J. Bridg. Eng. 2003, 8, 374-382. [CrossRef]

35. Liu, Y.; Frangopol, D.M. Utility and Information Analysis for Optimum Inspection of Fatigue-Sensitive Structures. J. Struct. Eng. 2019, 145, 04018251. [CrossRef]

36. Agusta, A.; Thöns, S.; Leira, B.J. Value of Information-Based Inspection Planning for Offshore Structures. Vol. 1 Offshore Technol. 2017, 3, 35. [CrossRef] 
37. Luque, J.; Straub, D. Risk-based optimal inspection strategies for structural systems using dynamic Bayesian networks. Struct. Saf. 2019, 76, 68-80. [CrossRef]

38. Straub, D. Value of information analysis with structural reliability methods. Struct. Saf. 2014, 49, 75-85. [CrossRef]

39. Haladuick, S.; Dann, M.R. Value of information-based decision analysis of the optimal next inspection type for deteriorating structural systems. Struct. Infrastruct. Eng. 2018, 14, 1283-1292. [CrossRef]

40. Parr, M.J.; Connor, R.J.; Bowman, M. Proposed Method for Determining the Interval for Hands-on Inspection of Steel Bridges with Fracture Critical Members. J. Bridg. Eng. 2010, 15, 352-363. [CrossRef]

41. Nasrollahi, M.; Washer, G. Estimating Inspection Intervals for Bridges Based on Statistical Analysis of National Bridge Inventory Data. J. Bridg. Eng. 2015, 20, 04014104. [CrossRef]

42. Atadero, R.A.; Jia, G.; Abdallah, A.; Ozbek, M.E. Jia An Integrated Uncertainty-Based Bridge Inspection Decision Framework with Application to Concrete Bridge Decks. Infrastructures 2019, 4, 50. [CrossRef]

43. Jia, G.; Gardoni, P. State-dependent stochastic models: A general stochastic framework for modeling deteriorating engineering systems considering multiple deterioration processes and their interactions. Struct. Saf. 2018, 72, 99-110. [CrossRef]

44. FHWA. Recording and Coding Guide for the Structure Inventory and Appraisal of the Nation's Bridges Rep. No. FHWA-PD-96-001; Federal Highway Adminstration: Washington, DC, USA, 1995.

45. AASHTO. Manual for Bridge Element Inspection; AASHTO: Washington, DC, USA, 2013.

46. Li, M.; Wang, R.-Q.; Jia, G. Efficient dimension reduction and surrogate-based sensitivity analysis for expensive models with high-dimensional outputs. Reliab. Eng. Syst. Saf. 2020, 195, 106725. [CrossRef]

47. FHWA. Federal Highway Administration Nondestructive Evaluation (NDE) Web Manual. Available online: https:/ fhwaapps fhwa.dot.gov/ndep/TechniqueLocatorNew.aspx (accessed on 6 October 2020).

48. Hesse, A.A.; Atadero, R.A.; Ozbek, M.E. Using Expert Opinion to Quantify Uncertainty in and Cost of Using Nondestructive Evaluation on Bridges. Adv. Civ. Eng. 2017, 2017, 1-12. [CrossRef]

49. Zheng, R.; Ellingwood, B.R. Role of non-destructive evaluation in time-dependent reliability analysis. Struct. Saf. 1998, 20, 325-339. [CrossRef]

50. Enright, M.P.; Frangopol, D.M. Condition Prediction of Deteriorating Concrete Bridges Using Bayesian Updating. J. Struct. Eng. 1999, 125, 1118-1125. [CrossRef]

51. Akgul, F.; Frangopol, D.M. Lifetime Performance Analysis of Existing Reinforced Concrete Bridges. II: Application. J. Infrastruct. Syst. 2005, 11, 129-141. [CrossRef]

52. Marsh, P.S.; Frangopol, D.M. Reinforced concrete bridge deck reliability model incorporating temporal and spatial variations of probabilistic corrosion rate sensor data. Reliab. Eng. Syst. Saf. 2008, 93, 394-409. [CrossRef]

53. Kim, S.; Frangopol, D.M.; Zhu, B. Probabilistic Optimum Inspection/Repair Planning to Extend Lifetime of Deteriorating Structures. J. Perform. Constr. Facil. 2011, 25, 534-544. [CrossRef]

54. NCHRP. Manual on Service Life of Corrosion-Damaged Reinforced Concrete Bridge Superstructure Elements; Transportation Research Board of the National Academies: Washington, DC, USA, 2006.

55. Enright, M.P.; Frangopol, D.M. Maintenance Planning for Deteriorating Concrete Bridges. J. Struct. Eng. 1999, 125, 1407-1414. [CrossRef]

56. Taylor, B.R.; Qiao, Y.; Bowman, M.D.; Labi, S. The Economic Impact of Implementing Nondestructive Testing of Reinforced Concrete Bridge Decks in Indiana; FHWA/IN/JTRP-2016/20; Purdue e-Pubs: West Lafayette, Indiana, 2016.

57. Molina, F.J.; Alonso, C.; Andrade, C. Cover cracking as a function of rebar corrosion: Part 2-Numerical model. Mater. Struct. 1993, 26, 532-548. [CrossRef]

58. ACI. Prediction of Creep, Shrinkage and Temperature Effects: 2. American Concrete Institute Committe 209. Detroit; ACI: Farmington Hills, MI, USA, 1978; pp. 586-598.

59. Cheung, M.M.S.; So, K.K.L. Service Life Prediction and Management of Concrete Bridge Structures Due to Corrosion. J. Civ. Eng. Arch. 2015, 9, 1153-1166. [CrossRef]

60. Val, D.V.; Stewart, M.G.; Melchers, R.E. Life-Cycle Performance of RC Bridges: Probabilistic Approach. Comput. Civ. Infrastruct. Eng. 2000, 15, 14-25. [CrossRef]

61. Vu, K.A.T.; Stewart, M.G. Predicting the Likelihood and Extent of Reinforced Concrete Corrosion-Induced Cracking. J. Struct. Eng. 2005, 131, 1681-1689. [CrossRef]

62. Val, D.V.; Melchers, R.E. Reliability of Deteriorating RC Slab Bridges. J. Struct. Eng. 1997, 123, 1638-1644. [CrossRef]

63. Liu, T.; Weyers, R. Modeling the Dynamic Corrosion Process in Chloride Contaminated Concrete Structures. Cem. Concr. Res. 1998, 28, 365-379. [CrossRef]

64. Liu, Y. Modeling the Time-To Corrosion Cracking of the Cover Concrete in Chloride Contaminated Reinforced Concrete Structures; Virginia Tech: Blacksburg, VA, USA, 1996.

65. Yehia, S.; Abudayyeh, O.; Nabulsi, S.; Abdelqader, I. Detection of Common Defects in Concrete Bridge Decks Using Nondestructive Evaluation Techniques. J. Bridg. Eng. 2007, 12, 215-225. [CrossRef]

66. Washer, G.; Connor, R.; Nasrollahi, M.; Reising, R. Verification of the Framework for Risk-Based Bridge Inspection. J. Bridg. Eng. 2016, 21, 04015078. [CrossRef]

67. Soliman, M.; Frangopol, D.M.; Mondoro, A. A probabilistic approach for optimizing inspection, monitoring, and maintenance actions against fatigue of critical ship details. Struct. Saf. 2016, 60, 91-101. [CrossRef] 
68. Mori, Y.; Ellingwood, B.R. Maintaining Reliability of Concrete Structures. I: Role of Inspection/Repair. J. Struct. Eng. 1994, 120, 824-845. [CrossRef]

69. Enright, M.P.; Frangopol, D.M. Service-Life Prediction of Deteriorating Concrete Bridges. J. Struct. Eng. 1998, 124, 309-317. [CrossRef]

70. Tuutti, K. Corrosion of Steel in Concrete; Cement-Och Betonginst: Stockholm, Sweden, 1982.

71. Crank, J. The mathematics of diffusion, 2nd ed.; Oxford University Press: New York, NY, USA, 1975; p. 411.

72. Stewart, M.G. Spatial variability of pitting corrosion and its influence on structural fragility and reliability of RC beams in flexure. Struct. Saf. 2004, 26, 453-470. [CrossRef]

73. González, J.; Andrade, C.; Alonso, C.; Feliu, S. Comparison of rates of general corrosion and maximum pitting penetration on concrete embedded steel reinforcement. Cem. Concr. Res. 1995, 25, 257-264. [CrossRef] 